\title{
A Mixed Integer Linear Programming Approach for Optimal DER Portfolio, Sizing, and Placement in Multi-Energy Microgrids
}

\author{
Salman Mashayekh, Michael Stadler, Gonçalo Cardoso, and Miguel Heleno \\ Ernest Orlando Lawrence Berkeley National Lab, 1 Cyclotron Rd, MS: 90-1121, Berkeley, CA 94720 \\ Corresponding Author: Michael Stadler(MStadler@lbl.gov)
}

\begin{abstract}
Optimal microgrid design is a challenging problem, especially for multi-energy microgrids with electricity, heating, and cooling loads as well as sources, and multiple energy carriers. To address this problem, this paper presents an optimization model formulated as a mixed-integer linear program, which determines the optimal technology portfolio, the optimal technology placement, and the associated optimal dispatch, in a microgrid with multiple energy types. The developed model uses a multi-node modeling approach (as opposed to an aggregate single-node approach) that includes electrical power flow and heat flow equations, and hence, offers the ability to perform optimal siting considering physical and operational constraints of electrical and heating/cooling networks. The new model is founded on the existing optimization model DER-CAM, a state-of-the-art decision support tool for microgrid planning and design. The results of a case study that compares single-node vs. multi-node optimal design for an example microgrid show the importance of multi-node modeling. It has been shown that single-node approaches are not only incapable of optimal DER placement, but may also result in sub-optimal DER portfolio, as well as underestimation of investment costs.
\end{abstract}

\section{Keywords}

Multi-energy microgrid design, power flow, electrical network, heating and cooling network, mixedinteger linear program

\section{Nomenclature}

Decision variables and parameters are denoted with italic and non-italic fonts, respectively. Binary/integer variables are denoted with all-small letters. Vectors and matrices are denoted with bold small case letters and bold capital case letters, respectively.

\subsection{Sets and Indices}

西

time $(1, \ldots, 12 \times 3 \times 24): 12$ months, 3 day-types per month, and 24 hours per day-type month $(1, \ldots, 12)$ energy use: electricity $(\mathrm{EL})$, cooling $(\mathrm{CL})$, heating $(\mathrm{HT})$ generation technologies whose capacities are modeled with continuous variables (referred to as continuous generation technologies in this paper): photovoltaic (PV), solar thermal (ST), electric chiller (EC), boiler (BL), absorption chiller (AC) 


\begin{tabular}{|c|c|c|}
\hline 34 & \multirow[t]{3}{*}{ g } & generation technologies whose capacities are modeled with discrete variables (referred \\
\hline 35 & & to as discrete generation technologies in this paper): internal combustion engine (ICE), \\
\hline 36 & & micro-turbine (MT), fuel cell (FC) \\
\hline 37 & $\mathrm{~s}$ & storage technologies: electric storage (ES), heat storage (HS), cold storage (CS) \\
\hline 38 & j & all generation technologies $(g \cup \mathrm{c})$ \\
\hline 39 & $\mathrm{k}$ & generation and storage technologies whose capacities are modeled with continuous \\
\hline 40 & & variables (referred to as continuous technologies in this paper) (c $\cup \mathrm{s}$ ) \\
\hline 41 & $\mathrm{i}$ & all generation and storage technologies $(\mathrm{g} \cup \mathrm{c} \cup \mathrm{s})$ \\
\hline 42 & $\mathrm{p}$ & period of day (for tariff): on-peak, mid-peak, and off-peak \\
\hline 43 & $\mathrm{n}, \mathrm{n}^{\prime}$ & electrical/thermal nodes $(1,2, \ldots, N): \mathrm{n}$ and $\mathrm{n}^{\prime}$ are aliases \\
\hline 44 & 1.2 Electri & al and Thermal Network Parameters \\
\hline 45 & $\mathrm{~N}$ & number of nodes (electrical/thermal) \\
\hline 46 & $r_{n, n^{\prime}}, x_{n, n^{\prime}}$ & resistance/inductance of the line connecting node $n$ to $n^{\prime}$, i.e. line $\left(n, n^{\prime}\right), p u$ \\
\hline 47 & $\mathrm{Yr}_{\mathrm{n}, \mathrm{n}^{\prime}}, \mathrm{Yi}_{\mathrm{n}, \mathrm{n}^{\prime}}$ & real/imaginary term of Ybus for line $\left(n, n^{\prime}\right), p u$ \\
\hline 48 & $\mathrm{Zr}_{\mathrm{n}, \mathrm{n}^{\prime}}, \mathrm{Zi}_{\mathrm{n}, \mathrm{n}^{\prime}}$ & real/imaginary term of Zbus for line $\left(n, n^{\prime}\right), p u$ \\
\hline 49 & $\mathrm{Sb}$ & base apparent power, kVA \\
\hline 50 & $\mathrm{~V}_{0}$ & slack bus voltage, pu \\
\hline 51 & $\underline{\mathrm{V}}, \overline{\mathrm{V}}$ & minimum/maximum acceptable voltage magnitude, $\mathrm{pu}$ \\
\hline 52 & $\underline{\theta}, \bar{\theta}$ & minimum/maximum expected voltage angle, rad \\
\hline 53 & $\mathrm{Nv}$ & number of segments for linearization of current magnitude squared \\
\hline 54 & $\overline{\mathrm{Ir}}_{\mathrm{n}, \mathrm{n}^{\prime}}, \overline{\mathrm{Ii}}_{\mathrm{n}, \mathrm{n}^{\prime}}$ & maximum expected value of the real/imaginary current of line $\left(n, n^{\prime}\right), p u$ \\
\hline 55 & $\overline{\mathrm{I}}_{\mathrm{n}, \mathrm{n}^{\prime}}$ & current carrying capacity (ampacity) of line $\left(n, n^{\prime}\right), p u$ \\
\hline 56 & $\overline{\mathrm{S}}_{\mathrm{n}, \mathrm{n}^{\prime}}$ & power carrying capacity of line $\left(n, n^{\prime}\right)$, pu \\
\hline 57 & $\phi$ & generation/load power factor \\
\hline 58 & $\gamma_{\mathrm{n}, \mathrm{n}^{\prime}}$ & heat loss coefficient for heat transfer pipe $\left(n, n^{\prime}\right), \% / m$ \\
\hline 59 & $\overline{\operatorname{HtTr}}_{\mathrm{n}, \mathrm{n} \prime}$ & heat transfer capacity for pipe $\left(n, n^{\prime}\right), k W$ \\
\hline 60 & 1.3 Marke & and Tariff Data \\
\hline 61 & grd & binary parameter for the existence of a grid connection \\
\hline 62 & $\operatorname{CurPr}_{n, u}$ & load curtailment cost for energy use $\mathrm{u}$ at node $\mathrm{n}, \$ / \mathrm{kWh}$ \\
\hline 63 & CTax & tax on carbon emissions (onsite and offsite), $\$ / \mathrm{kg}$ \\
\hline 64 & $\mathrm{DmnRt}_{\mathrm{m}, \mathrm{p}}$ & power demand charge for month $\mathrm{m}$ and period $\mathrm{p}, \$ / \mathrm{kW}$ \\
\hline 65 & $\operatorname{ExpRt}_{\mathrm{t}}$ & energy rate for electricity export, $\$ / \mathrm{kWh}$ \\
\hline 66 & PurRt $_{t}$ & energy rate for electricity purchase, $\$ / \mathrm{kWh}$ \\
\hline 67 & $\overline{\text { UtExp }}$ & maximum allowable electricity export to the grid, $\mathrm{kW}$ \\
\hline 68 & 1.4 Techn & logy Data for Investment \\
\hline 69 & $\mathrm{Ann}_{\mathrm{i}}$ & annuity rate for technology i \\
\hline 70 & $\mathrm{CFix}_{\mathrm{k}}$ & fixed capital cost of continuous technology $k, \$$ \\
\hline 71 & $\mathrm{CVar}_{\mathrm{k}}$ & variable capital cost of continuous technology $\mathrm{k}, \$ / \mathrm{kW}$ \\
\hline 72 & $\overline{\mathrm{DERP}}_{\mathrm{g}}$ & power rating of discrete generation technology $\mathrm{g}, \mathrm{kW}$ \\
\hline
\end{tabular}


DERCap $_{\mathrm{g}} \quad$ turnkey capital cost of discrete generation technology $\mathrm{g}, \$ / \mathrm{kW}$

741.5 Technology Data for Operation

75 COPa, $\mathrm{COPe}$ absorption/electric chiller coefficient of performance

76 DERMFx $_{\mathrm{i}} \quad$ fixed annual operation and maintenance cost of technology $\mathrm{i}, \$ / \mathrm{kW}$-capacity

77 DERMVr $_{i} \quad$ variable annual operation and maintenance cost of technology $\mathrm{i}, \$ / \mathrm{kWh}$

78 DERGnCst $_{j}$ generation cost of technology $\mathrm{j}, \$ / \mathrm{kWh}$

79 SolEff $_{\mathrm{c}, \mathrm{t}} \quad$ solar radiation conversion efficiency of generation technology $\mathrm{c} \in\{\mathrm{PV}, \mathrm{ST}\}$

$80 \mathrm{ScPkEff}_{\mathrm{c}} \quad$ theoretical peak solar conversion efficiency of generation technology $\mathrm{c} \in\{\mathrm{PV}, \mathrm{ST}\}$

$81 \mathrm{SCEff}_{\mathrm{S}}$, SDEff $_{\mathrm{S}}$ charging/discharging efficiency of storage technology s

$82 \overline{\mathrm{SCRt}}_{\mathrm{s}}, \overline{\mathrm{SDRt}}_{\mathrm{s}}$ max charge/discharge rate of storage technology $\mathrm{s}, \mathrm{kW}$

$83 \mathrm{SOC}_{\mathrm{s}}, \overline{\mathrm{SOC}}_{\mathrm{s}} \quad \mathrm{min} / \mathrm{max}$ state of charge for storage technology s, \%

$84 \varphi_{\mathrm{s}} \quad$ losses due to self-discharge in storage technology s, \%

$85 \alpha_{j} \quad$ useful heat recovery from a unit of electricity generated by technology $\mathrm{j}, \mathrm{kW} / \mathrm{kW}$

$86 \eta_{j} \quad$ electrical efficiency of generation technology $\mathrm{j}$

$87 \mathrm{MkCRt}_{\mathrm{t}} \quad$ marginal carbon emissions from marketplace generation, $\mathrm{kg} / \mathrm{kWh}$

$88 \mathrm{GCRt}_{\mathrm{j}} \quad$ carbon emissions rate from generation technology $\mathrm{j}, \mathrm{kg} / \mathrm{kWh}$

$89 \quad 1.6$ Site and Location Parameters

90 Solar $r_{t} \quad$ average fraction of maximum solar insolation received during time $t, \%$

$91 \mathrm{Ld}_{\mathrm{n}, \mathrm{u}, \mathrm{t}} \quad$ customer load for end-use $\mathrm{u}$ at node $\mathrm{n}, \mathrm{kW}$

921.7 Decision/State Variables for Investment

$93 \operatorname{pur}_{\mathrm{n}, \mathrm{k}} \quad$ binary purchase decision for continuous technology $\mathrm{k}$ at node $\mathrm{n}$

$94 \operatorname{Cap}_{\mathrm{n}, \mathrm{k}} \quad$ installed capacity of continuous technology $\mathrm{k}$ at node $\mathrm{n}, \mathrm{kW}$ or $\mathrm{kWh}$

$95 \quad i n v_{\mathrm{n}, \mathrm{g}} \quad$ integer units of discrete generation technology $\mathrm{g}$ at node $\mathrm{n}$

961.8 Decision/State Variables for Operation

$97 \quad p s b_{\mathrm{n}, \mathrm{t}} \quad$ binary electricity purchase/sell decision at node $\mathrm{n}$

$98 U t E x p_{n, t} \quad$ electricity exported to the utility at node $\mathrm{n}, \mathrm{kW}$

$99 U t P u r_{\mathrm{n}, \mathrm{t}} \quad$ electricity purchased from the utility at node $\mathrm{n}, \mathrm{kW}$

$100 \operatorname{MaxPur}_{\mathrm{n}, \mathrm{m}, \mathrm{p}}$ maximum electricity purchased from the utility during period $\mathrm{p}$ of month $\mathrm{m}, \mathrm{kW}$

$101 S O C_{\mathrm{n}, \mathrm{s}, \mathrm{t}} \quad$ state of charge for storage technology s at node $\mathrm{n}, \%$

$102 \operatorname{SIn}_{\mathrm{n}, \mathrm{s}, \mathrm{t}} \quad$ energy input to storage technology s at node $\mathrm{n}, \mathrm{kWh}$

103 SOut $_{\mathrm{n}, \mathrm{s}, \mathrm{t}} \quad$ energy output from storage technology s at node $\mathrm{n}, \mathrm{kWh}$

$104 \quad \operatorname{LdCur}_{\mathrm{n}, \mathrm{u}, \mathrm{t}} \quad$ customer load not met in energy use $\mathrm{u}$ at node $\mathrm{n}, \mathrm{kW}$

105 Gen $_{\mathrm{n}, \mathrm{j}, \mathrm{u}, \mathrm{t}} \quad$ output of technology $\mathrm{j}$ to meet energy use $\mathrm{u}$ at node $\mathrm{n}, \mathrm{kW}$

$106 \operatorname{HtTr}_{\mathrm{n}, \mathrm{n}^{\prime}, \mathrm{t}} \quad$ heat flow from node $\mathrm{n}$ to $\mathrm{n}^{\prime}, \mathrm{kW}$

$107 V r_{\mathrm{n}, \mathrm{t}}, V i_{\mathrm{n}, \mathrm{t}} \quad$ real/imaginary voltage at node $\mathrm{n}, \mathrm{pu}$

$108 P g_{\mathrm{n}, \mathrm{t}}, Q g_{\mathrm{n}, \mathrm{t}} \quad$ injected active/reactive power at node $\mathrm{n}, \mathrm{pu}$

$109 S g_{\mathrm{n}, \mathrm{t}} \quad$ injected apparent power at node $\mathrm{n}, \mathrm{pu}$

$110 P \operatorname{Ploss}_{\mathrm{t}}$, Lloss $_{\mathrm{t}}$ network active/reactive power loss at time $\mathrm{t}, \mathrm{pu}$

$111 S_{\mathrm{n}, \mathrm{n}^{\prime}, \mathrm{t}} \quad$ apparent power of line $\left(\mathrm{n}, \mathrm{n}^{\prime}\right), \mathrm{pu}$ 
$I r_{\mathrm{n}, \mathrm{n}^{\prime}, \mathrm{t}}, I i_{\mathrm{n}, \mathrm{n}^{\prime}, \mathrm{t}} \quad$ real/imaginary current of line $\left(\mathrm{n}, \mathrm{n}^{\prime}\right), \mathrm{pu}$

$113 \quad \operatorname{Ir} S q_{\mathrm{n}, \mathrm{n}^{\prime}, \mathrm{t}}$

linear approximation of $\left|I r_{\mathrm{n}, \mathrm{n}^{\prime}, \mathrm{t}}\right|^{2}, \mathrm{pu}^{2}$

114

$\operatorname{IiS} q_{\mathrm{n}, \mathrm{n}^{\prime}, \mathrm{t}}$

linear approximation of $\left|I i_{\mathrm{n}, \mathrm{n}^{\prime}, \mathrm{t}}\right|^{2}, \mathrm{pu}^{2}$

\section{Introduction}

116 The attention towards microgrids is constantly increasing with a fast pace, as a result of their benefits in 117 terms of renewable integration, low carbon footprint, reliability and resiliency, power quality, and

118 economics. Global environmental concerns are pushing forward and providing incentives for the 119 deployment of renewable energy technologies, e.g. photovoltaics (PV) and wind. Most developed 120 countries have set their renewable penetration goals. As a consequence, renewable energy technologies 121 are rapidly advancing towards lower costs and higher efficiencies, making their deployments even more 122 compelling. Also, resiliency concerns in the face of natural disasters have made (islandable) microgrids 123 more popular, especially for critical facilities. The NY REV (New York's Reforming of the Energy Vision) 124 Initiative [1] is an example of amplified attention towards microgrids, following big disruptions caused 125 by the Hurricane Sandy in the US North East. Microgrids provide benefits to the utilities, too, since they 126 are a much better alternative compared to distributed and uncoordinated deployment of renewable 127 energy resources.

128 A microgrid offers a cluster of small sources, storage systems, and loads, within clearly-defined electrical 129 boundaries, which presents itself to the main grid as a single, flexible, and controllable entity [2]. By 130 introducing on-site generation, storage, and bidirectional power flow, microgrids can be seen as a 131 valuable resource to the grid, while also being more independent from it [3]. This flexible resource, if 132 optimally designed and operated, also provides cost saving benefits to the customers. Microgrids, 133 however, are complex energy systems that require specific infrastructure, resource coordination, and 134 information flows [3], and the complexity increases in the presence of technologies that tie together electrical, heating, and cooling energy flows. Such multi-energy microgrids with combined heat and power (CHP) and absorption chilling offer better efficiencies and savings through utilization of waste heat [4],[5]. The high level of complexity and the potential for cost savings, when also factoring in the high investment cost of microgrids, will help appreciate the challenging problem of microgrid design, especially for multi-energy microgrids (i.e., microgrids in which electricity, heat, cooling, and fuels interact with each other, presenting the opportunity to enhance technical, economic and environmental performance [6]).

Several papers in the literature have reviewed the existing tools and computer models for renewable energy integration and microgrid planning and design [7-12]. A comprehensive microgrid investment and planning optimization formulation must address a) power generation mix selection and sizing, b) resource siting and allocation, and c) operation scheduling [10]. In order to take full advantage of excess heat it must simultaneously consider electricity, cooling, and heating energy uses in the microgrid. However, most of the existing formulations focus on individual sub-problems and do not include the whole set of problems or include them without enough depth. Table 1 provides a summary of the recent encompassing all of the aforementioned pieces. 
151 On one side of the spectrum are formulations that include details of the electrical network and do not 152 consider the thermal network. Among them are some of the distribution network planning formulations 153 that consider distributed and renewable energy resources (DER). A review of optimal distributed 154 renewable generation planning approaches is provided in [13]. These formulations [14-16] share some 155 of the same characteristics with the microgrid design problem, mainly since they determine the size and 156 location of DERs to be installed and the optimal dispatch associated with the upgraded network. 157 However, the generation mix is limited and the focus is only on electrical energy use. Similarly, some 158 microgrid design formulations [17],[18] only tackle electrical energy, neglecting heating and cooling 159 energy uses. On the other side of the spectrum, district or neighborhood-level heating design 160 optimization formulations focus on the thermal energy and its flow in the network, but do not consider 161 electrical energy use, e.g. [19-21]; or take electrical energy use into account but neglect the electrical 162 network, e.g. [22-24], weakening the ability to perform DER optimal placement.

163 References [25-31] feature microgrid design formulations that model (to some extent) both electrical 164 and thermal networks and present the most relevant work to this paper. Omu et. al. [25] formulated a 165 mixed integer linear program for optimum technology selection, unit sizing and allocation, and network 166 design of a distributed energy system that meets the electricity and heating demands of a cluster of 167 buildings. This work, however, models electrical energy as a commodity whose transfer from one 168 location to another can be arbitrarily decided, neglecting power flow constraints or Kirchhoff laws. 169 Similarly, the approaches presented in [26-28] for design and planning of urban and distributed energy 170 systems do not include power flow equations. Yang et. al. [29] proposed another approach for 171 integrated design of heating, cooling, and electrical power distribution networks, but did not include 172 electrical power flow equations.

173 In another example, Morvaj et. al. [30] developed a mixed integer linear program for the optimal design 174 of distributed energy systems, in which linearized AC power flow equations and heat transfer equations 175 were integrated, but cooling energy use was neglected. Similarly, Basu et. al. [31] proposed an approach 176 to optimally determine the size, location, and type of CHP-based DERs in microgrids, using power loss 177 sensitivity to guide the optimization in siting the DERs. Although both electrical and heating energy uses 178 and networks are modeled, cooling is neglected. Also, the formulation is nonlinear and solves using a 179 stochastic approach. Unlike linear formulations, nonlinear formulations do not efficiently scale and it is 180 not guaranteed to find the best solution. 
Table 1 Summary of the most relevant formulations in the current literature

\begin{tabular}{|c|c|c|c|c|c|c|}
\hline \multirow[b]{2}{*}{ Ref. } & \multicolumn{3}{|l|}{ Energy Use } & \multicolumn{2}{|c|}{ Electrical Distribution Network } & \multirow{2}{*}{$\begin{array}{l}\text { Heat Transfer Network } \\
\text { Capacity } \\
\text { Constraints }\end{array}$} \\
\hline & Electricity & Heating & Cooling & $\begin{array}{l}\text { Capacity } \\
\text { Constraints }\end{array}$ & $\begin{array}{l}\text { Voltage Constraints } \\
\text { (Power Flow Equations) }\end{array}$ & \\
\hline [14] & $x$ & & & $x$ & $x$ & \\
\hline [15] & $x$ & & & $x$ & $x$ & \\
\hline$[16]$ & $x$ & & & $x$ & $x$ & \\
\hline$[17]$ & $x$ & & & $x$ & $x$ & \\
\hline [18] & $x$ & & & $x$ & $x$ & \\
\hline [19] & & $x$ & & & & $x$ \\
\hline$[20]$ & & $x$ & & & & $x$ \\
\hline [21] & & $x$ & & & & $x$ \\
\hline$[22]$ & $x$ & $x$ & & & & $x$ \\
\hline [23] & $x$ & $x$ & & & & $x$ \\
\hline$[24]$ & $x$ & $x$ & & & & $x$ \\
\hline$[25]$ & $x$ & $x$ & & $x$ & & $x$ \\
\hline$[26]$ & $x$ & $x$ & & $x$ & & $x$ \\
\hline$[27]$ & $x$ & $x$ & & $x$ & & $x$ \\
\hline [28] & $x$ & $x$ & & $x$ & & $x$ \\
\hline [29] & $x$ & $x$ & $x$ & $x$ & & $x$ \\
\hline [30] & $x$ & $x$ & & $x$ & $x$ & $x$ \\
\hline [31] & $x$ & $x$ & & $x$ & $x$ & $x$ \\
\hline This Paper & $x$ & $x$ & $x$ & $x$ & $x$ & $x$ \\
\hline
\end{tabular}

This paper builds on the existing work in the literature, and formulates the problem of optimal design (DER sizing, allocation, and operation) of microgrids as a mixed integer linear program. The contributions of this work are threefold:

- First, we propose an integrated design approach in which electrical, heating, and cooling loads and sources are modeled, in order to take full advantage of excess heat in the microgrid and enhance the overall system efficiency.

- Second, our formulation considers the limitations of the electrical and heat transfer networks in the design and dispatch, allowing for the optimal placement of the DER technologies. To this end, we integrate a set of linear heat transfer equations that include network losses. We also integrate a set of linearized AC power flow equations into the problem that model active and reactive power flow in the network and hence, allows imposing of cable capacity and bus voltage constraints.

- Third, since minimization of network losses is one of the important factors in optimal technology placement, we propose a novel approach to integrate a linear approximation of electrical network active and reactive power losses into the optimization problem.

This paper is organized as follows. Section 3 presents the developed model for the optimal microgrid design problem and discusses the details of the optimization objective and constraints. Next, an illustrative case study is presented in section 4 and the results are elaborated. The paper summary and future work are provided in section 5. 
201

202

203

204

205

206

207

208

209

210

211

212

213

214

215

216

217

218

219

220

221

222

223

224

225

226

\section{Developed Optimization Model}

We present the mathematical formulation for the integrated design of multi-energy microgrids. The presented model is founded on the existing optimization model in DER-CAM (Distributed Energy Resources Customer Adoption Model) [32], developed by Lawrence Berkeley National Laboratory. DERCAM is used extensively to address the problem of optimal investment and dispatch of microgrids under multiple settings. DER-CAM is one of the few optimization tools of its kind that is available for public use and stable versions can be accessed freely using a web interface [33]. The key inputs in DER-CAM are customer loads, utility tariffs, and techno-economic data for DER technologies. Key optimization outputs include the optimal installed on-site capacity and dispatch of selected technologies, demand response measures, and energy costs.

The new model proposed in this paper alleviates the need to iterate between a microgrid optimizationbased design tool and an electrical power flow tool or a heat transfer modeling tool since it considers the microgrid's electrical and thermal networks and their limitations. To enable reasonable and practical optimization run times, we formulate the problem in the form of a mixed integer linear program. To that end, component and network models are simplified and linearized. Our previous analysis of the existing models in DER-CAM [34-36] and our analysis of the new models developed in this paper (presented in section 4) ensure the adequacy of the models and validate the simplifications.

\subsection{Microgrid Model}

We consider a general microgrid structure as shown in Figure 1 with electrical and thermal networks. The electrical network can be either meshed or radial. Similarly, the piping network can have any arbitrary configuration. The microgrid may or may not have a utility connection. The load at each node is composed of several end-uses including electricity-only (mainly plug loads), heating (water and space heating), and cooling loads. The objective is to determine the optimal portfolio, capacity, and placement of various DER technologies that minimize the overall investment and operation cost of the microgrid, while taking into account electrical and thermal network losses and constraints, as well as operational limits of various technologies.

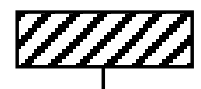

Macrogrid (Utility)
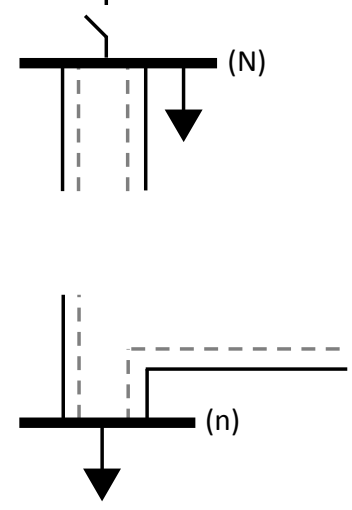
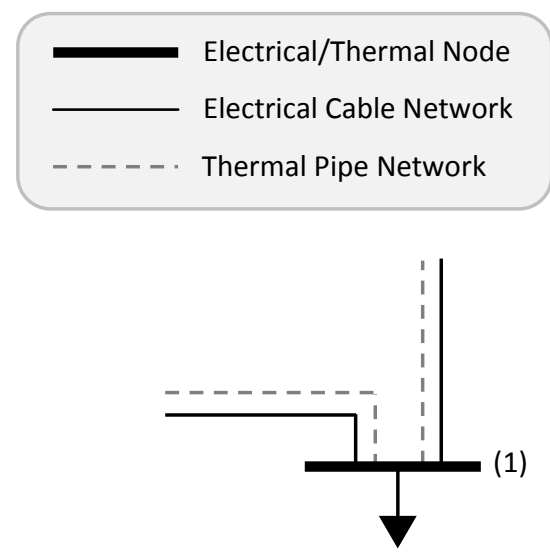


\subsection{Continuous vs. Discrete Investment Decision Variables}

231 We model DER capacities for different technologies using a continuous or discrete variable: If a technology is available in small enough modules and the capital costs can be represented by a linear cost function, the optimal capacity to be installed is modeled as a continuous variable, significantly lowering computational time. These technologies are referred to as continuous technologies in this paper. Examples of continuously modeled DER technologies are PV, battery, and absorption chilling. Discrete variables are used otherwise. These technologies are referred to as discrete technologies in this paper. Examples of discrete generation technologies are internal combustion engines and microturbines. Each node in Figure 1 can host continuous technologies (for which $\operatorname{Cap}_{\mathrm{n}, \mathrm{k}}$ is the capacity to be installed) and discrete technologies (for which $i n v_{\mathrm{n}, \mathrm{g}}$ is the number of units to be installed).

\subsection{Time Resolution}

241 The total investment and operation costs are minimized over a typical year, where each month is 242 modeled with up to three representative hourly load profiles of a) week day, b) weekend day, and c) 243 peak day (outlier). Therefore, a typical year is modeled with $12 \times 3 \times 24=864$ time-steps. Due to the 244 hourly time-step, energy and power are numerically identical.

\subsection{Objective Function}

246 The objective is to minimize the overall microgrid investment and operation cost, though it is also 247 possible to minimize emissions, or a combination of costs and emissions. Equation (1) shows that the 248 objective function includes: annualized investment costs of discrete and continuous technologies; total 249 cost of electricity purchase inclusive of carbon taxation; demand charges; electricity export revenues; 250 generation cost for electrical, heating, or cooling technologies inclusive of their variable maintenance

251 costs; fixed maintenance cost of discrete and continuous technologies; carbon taxation on local 252 generation; and load curtailment costs. 


$$
\begin{aligned}
& C=\sum_{\mathrm{n}, \mathrm{g}} i n v_{\mathrm{n}, \mathrm{g}} \cdot \overline{\mathrm{DERP}}_{\mathrm{g}} \cdot \mathrm{DERCap}_{\mathrm{g}} \cdot \mathrm{Ann}_{\mathrm{g}} \\
& +\sum_{\mathrm{n}, \mathrm{k}}\left(\operatorname{CFix}_{\mathrm{k}} \cdot \operatorname{pur}_{\mathrm{n}, \mathrm{k}}+\mathrm{CVar}_{\mathrm{k}} \cdot \operatorname{Cap}_{\mathrm{n}, \mathrm{k}}\right) \cdot \mathrm{Ann}_{\mathrm{k}} \\
& +\sum_{\mathrm{n}, \mathrm{t}} \text { UtilPur }_{\mathrm{n}, \mathrm{t}}\left(\text { PurRt }_{\mathrm{t}}+\mathrm{CTax} \cdot \mathrm{MkCRt}_{\mathrm{t}}\right) \\
& +\sum_{\mathrm{n}, \mathrm{m}, \mathrm{p}} \operatorname{DmnRt}_{\mathrm{m}, \mathrm{p}} \cdot \operatorname{MaxPur}_{\mathrm{n}, \mathrm{m}, \mathrm{p}} \\
& -\sum_{\mathrm{n}, \mathrm{t}} \operatorname{ExpRt}_{\mathrm{t}} \cdot U t \operatorname{Exp}_{\mathrm{n}, \mathrm{t}} \\
& +\sum_{\mathrm{n}, \mathrm{j}, \mathrm{t}} \operatorname{Gen}_{\mathrm{n}, \mathrm{j}, \mathrm{t}}\left(\mathrm{DERGnCst}_{\mathrm{j}}+\mathrm{DERMVr}_{\mathrm{j}}\right) \\
& +\sum_{\mathrm{n}, \mathrm{g}} \operatorname{inv}_{\mathrm{n}, \mathrm{g}} \cdot \overline{\mathrm{DERP}}_{\mathrm{g}} \cdot \operatorname{DERMFx}_{\mathrm{g}}+\sum_{\mathrm{n}, \mathrm{k}} \operatorname{Cap}_{\mathrm{n}, \mathrm{k}} \cdot \operatorname{DERMFx}_{\mathrm{k}} \\
& +\sum_{\mathrm{n}, \mathrm{j}, \mathrm{t}} \operatorname{Gen}_{\mathrm{n}, \mathrm{j}, \mathrm{t}} \cdot \frac{1}{\eta_{\mathrm{j}}} \cdot \mathrm{GCRt}_{j} \cdot \mathrm{CTax} \\
& +\sum_{\mathrm{n}, \mathrm{u}, \mathrm{t}} \operatorname{LdCur}_{\mathrm{n}, \mathrm{u}, \mathrm{t}} \cdot \operatorname{CurPr}_{\mathrm{n}, \mathrm{u}}
\end{aligned}
$$

\subsection{Electrical Balance}

To integrate electrical balance equations for the network, i.e. electrical power flow, an explicit linear model was adopted [37] that approximates node (bus) voltages in meshed/radial balanced distribution networks. Equations (4)-(6) show how real and imaginary terms of node voltages are calculated for nonslack and slack buses in the Cartesian coordinates, based on the network impedances and node injection powers. We assume the microgrid's slack (reference) bus is the last node, i.e. node $\mathrm{N}$, and its voltage is fixed at $V_{0} \angle 0^{\circ}$ as shown in (6).

The net injected power at a node, as shown in (2), takes into account utility import and export at the node, local generation at the node, load and load curtailment, electric chiller consumption at the node, and battery charging or discharging. To simplify the formulation presentation, we assume a constant power factor $\phi$ for all power injections, as shown in (3). This assumption, however, can be easily expanded to consider different power factors for various loads and DERs.

$$
\begin{aligned}
\mathrm{Sb} \cdot P g_{\mathrm{n}, \mathrm{t}} & =U t P u r_{\mathrm{n}, \mathrm{t}}-U t \operatorname{Exp}_{\mathrm{n}, \mathrm{t}} \\
& +\sum_{\mathrm{j} \in\{\mathrm{PV}, \mathrm{ICE}, \mathrm{MC}, \mathrm{FC}\}} \operatorname{Gen}_{\mathrm{n}, \mathrm{j}, \mathrm{t}} \\
& -\left(\mathrm{Ld}_{\mathrm{n}, \mathrm{u}=\mathrm{EL}, \mathrm{t}}-L d C u r_{\mathrm{n}, \mathrm{u}=\mathrm{EL}, \mathrm{t}}\right)-\frac{1}{\mathrm{COPe}} \cdot \operatorname{Gen}_{\mathrm{n}, \mathrm{c}=\mathrm{EC}, \mathrm{t}} \\
& +S O u t_{\mathrm{n}, \mathrm{s}=\mathrm{ES}, \mathrm{t}} \cdot \operatorname{SDEff}_{\mathrm{s}=\mathrm{ES}}-\frac{1}{\mathrm{SCEff}_{\mathrm{s}=\mathrm{ES}}} \cdot \operatorname{SIn}_{\mathrm{n}, \mathrm{S}=\mathrm{ES}, \mathrm{t}} \\
& Q g_{\mathrm{n}, \mathrm{t}}=P g_{\mathrm{n}, \mathrm{t}} \cdot \tan (\operatorname{acos} \phi) ; \mathrm{n} \neq \mathrm{N} \\
V r_{\mathrm{n}, \mathrm{t}}=\mathrm{V}_{0}+ & \frac{1}{\mathrm{~V}_{0}} \sum_{\mathrm{n}^{\prime} \neq \mathrm{N}}\left(\mathrm{Zr}_{\mathrm{n}, \mathrm{n}^{\prime}} \cdot P g_{\mathrm{n}, \mathrm{t}}+\mathrm{Zi}_{\mathrm{n}, \mathrm{n}^{\prime}} \cdot Q g_{\mathrm{n}, \mathrm{t}}\right) ; \mathrm{n} \neq \mathrm{N}
\end{aligned}
$$




$$
\begin{gathered}
V i_{\mathrm{n}, \mathrm{t}}=\mathrm{V}_{0}+\frac{1}{\mathrm{~V}_{0}} \sum_{\mathrm{n}^{\prime} \neq \mathrm{N}}\left(\mathrm{Zi}_{\mathrm{n}, \mathrm{n}^{\prime}} \cdot P g_{\mathrm{n}, \mathrm{t}}-\mathrm{Zr}_{\mathrm{n}, \mathrm{n}^{\prime}} \cdot Q g_{\mathrm{n}, \mathrm{t}}\right) ; \mathrm{n} \neq \mathrm{N} \\
V r_{\mathrm{n}, \mathrm{t}}=\mathrm{V}_{0}, V i_{\mathrm{n}, \mathrm{t}}=0 ; \mathrm{n}=\mathrm{N}
\end{gathered}
$$

The existence of the practical approximate power flow solution in (4)-(6) requires the network to meet the condition

$$
\mathrm{V}_{0}^{2}>4 \cdot\|\mathbf{Z}\|^{*} \cdot\left\|\boldsymbol{s}_{\mathrm{t}}\right\|
$$

in which $\mathbf{Z}$ is the network Zbus matrix without the slack bus row and column, and $\boldsymbol{s}_{\mathrm{t}}$ is the vector of apparent power injections for non-slack buses. The standard 2-norm $\|\cdot\|$ for the vector $\boldsymbol{s}_{\mathrm{t}}$ is defined as

$$
\left\|\boldsymbol{s}_{\mathrm{t}}\right\| \triangleq \sqrt{\sum_{\mathrm{n} \neq \mathrm{N}}\left|S g_{\mathrm{n}, \mathrm{t}}\right|^{2}}
$$

Also, the norm $\|\cdot\|^{*}$ for a matrix is defined as the maximum of the 2-norm values of its row vectors [37]. We refer to this constraint as the "approximate power flow existence condition" in this paper.

In the above condition, $\mathrm{V}_{0}^{2}$ and $\|\mathbf{Z}\|^{*}$ are parameters known before solving the optimization (i.e., fixed parameters). However, $\left\|\boldsymbol{s}_{t}\right\|$ at any given time $t$ depends on the dispatch, and will not be known until after solving the optimization. To ensure the validity of the integrated power flow model for a microgrid under study, we propose two options: The first option is to assume the model is valid and run the optimization. Then assess the criterion based on the optimization results (post-optimization assessment). Alternatively, in the second option we will find (in the following paragraph) an upper bound for the $\left\|s_{\mathrm{t}}\right\|$, which can be used to develop a sufficient condition.

The injection at a bus is limited by the capacity of the lines connected to the bus as shown in (7), setting an upper bound for the $\left\|\boldsymbol{s}_{t}\right\|$ as shown in (8). Consequently, the sufficient condition of (9) is obtained that can be assessed using only the network parameters (which are known before solving the optimization).

$$
\begin{gathered}
S g_{\mathrm{n}, \mathrm{t}}=\sum_{\mathrm{n}^{\prime}} S_{\mathrm{n}, \mathrm{n}^{\prime}, \mathrm{t}} \rightarrow\left|S g_{\mathrm{n}, \mathrm{t}}\right| \leq \sum_{\mathrm{n}^{\prime}}\left|S_{\mathrm{n}, \mathrm{n}^{\prime}, \mathrm{t}}\right| \leq \sum_{\mathrm{n}^{\prime}} \overline{\mathrm{S}}_{\mathrm{n}, \mathrm{n}^{\prime}} \\
\left\|\boldsymbol{s}_{\mathrm{t}}\right\| \leq \sqrt{\sum_{\mathrm{n} \neq \mathrm{N}}\left(\sum_{\mathrm{n}^{\prime}} \overline{\mathrm{S}}_{\mathrm{n}, \mathrm{n}^{\prime}}\right)^{2}} \\
\sqrt{\sum_{\mathrm{n} \neq \mathrm{N}}\left(\sum_{\mathrm{n}^{\prime}}\left|\overline{\mathrm{S}}_{\mathrm{n}, \mathrm{n}^{\prime}}\right|\right)^{2}} \leq \frac{1}{4 \cdot\|\mathbf{Z}\|^{*}} \cdot \mathrm{V}_{0}^{2}
\end{gathered}
$$

One of the important factors that drives the optimal placement of distributed energy resources is the minimization of network losses. To account for losses in this formulation, we add equation (10) that ensures total active/reactive power injection (generation minus consumption) equals total 
active/reactive power loss in the system. To calculate network losses in (11)-(12) we use $\operatorname{IrS} q_{\mathrm{n}, \mathrm{n}^{\prime}, \mathrm{t}}$ and

$289 I i S q_{\mathrm{n}, \mathrm{n}^{\prime}, \mathrm{t}}$ that are linear approximations of $\left|I r_{\mathrm{n}, \mathrm{n}^{\prime}, \mathrm{t}}\right|^{2}$ and $\left|I i_{\mathrm{n}, \mathrm{n}^{\prime}, \mathrm{t}}\right|^{2}$, respectively, and will be discussed in 290 section 3.6.

$$
\begin{aligned}
& \sum_{\mathrm{n}} P g_{\mathrm{n}, \mathrm{t}}=P \operatorname{Ploss}_{\mathrm{t}}, \sum_{\mathrm{n}} Q g_{\mathrm{n}, \mathrm{t}}=\operatorname{Qloss}_{\mathrm{t}} \\
& \operatorname{Ploss}_{\mathrm{t}}=\frac{1}{2} \sum_{\mathrm{n}, \mathrm{n}^{\prime}} \mathrm{r}_{\mathrm{n}, \mathrm{n}^{\prime}} \cdot\left(\left|I r_{\mathrm{n}, \mathrm{n}^{\prime}, \mathrm{t}}\right|^{2}+\left|I i_{\mathrm{n}, \mathrm{n}^{\prime}, \mathrm{t}}\right|^{2}\right) \approx \frac{1}{2} \sum_{\mathrm{n}, \mathrm{n}^{\prime}} \mathrm{r}_{\mathrm{n}, \mathrm{n}^{\prime}} \cdot\left(I r S q_{\mathrm{n}, \mathrm{n}^{\prime}, \mathrm{t}}+I i S q_{\mathrm{n}, \mathrm{n}^{\prime}, \mathrm{t}}\right) \\
& \operatorname{Qloss}_{\mathrm{t}}=\frac{1}{2} \sum_{\mathrm{n}, \mathrm{n}^{\prime}} \mathrm{x}_{\mathrm{n}, \mathrm{n}^{\prime}} \cdot\left(\left|I r_{\mathrm{n}, \mathrm{n}^{\prime}, \mathrm{t}}\right|^{2}+\left|I i_{\mathrm{n}, \mathrm{n}^{\prime}, \mathrm{t}}\right|^{2}\right) \approx \frac{1}{2} \sum_{{\mathrm{n}, \mathrm{n}^{\prime}}} \mathrm{x}_{\mathrm{n}, \mathrm{n}^{\prime}} \cdot\left(I r S q_{\mathrm{n}, \mathrm{n}^{\prime}, \mathrm{t}}+I i S q_{\mathrm{n}, \mathrm{n}^{\prime}, \mathrm{t}}\right)
\end{aligned}
$$

291

292

293

294

295

296

297

298

299

300

301

302

\subsection{Cable Current Constraints}

To integrate cable current capacity (ampacity) constraints, (13)-(14) calculate the real and imaginary terms of the current in the Cartesian coordinates. To estimate $|I r|^{2}$ and $|I i|^{2}$, the square curve is piecewise linearized and relaxed as shown in Figure 2. Consequently, $\operatorname{IrSq}$ and $\operatorname{IiSq}$ are calculated using a series of linear inequality equations, as shown in (15)-(18). Equations (15) and (16) are for the positive and negative values of $I r$, respectively. Similarly, (17) and (18) are related to the positive and negative values of $I i . \Delta \mathrm{Ir}$ and $\Delta \mathrm{Ii}$ in these equations are calculated in (19). Equation (20) enforces the ampacity constraint. As mentioned earlier, $\operatorname{IrS} q$ and $\operatorname{IiS} q$ are used for loss estimation, too.

$$
\begin{aligned}
& I r_{\mathrm{n}, \mathrm{n}^{\prime}, \mathrm{t}}=-\mathrm{Yr}_{\mathrm{n}, \mathrm{n}^{\prime}} \cdot\left(V r_{\mathrm{n}, \mathrm{t}}-V r_{\mathrm{n}^{\prime}, \mathrm{t}}\right)+\mathrm{Yi}_{\mathrm{n}, \mathrm{n}^{\prime}} \cdot\left(V i_{\mathrm{n}, \mathrm{t}}-V i_{\mathrm{n}^{\prime}, \mathrm{t}}\right) \\
& I i_{\mathrm{n}, \mathrm{n}^{\prime}, \mathrm{t}}=-\mathrm{Yi}_{\mathrm{n}, \mathrm{n}^{\prime}} \cdot\left(V r_{\mathrm{n}, \mathrm{t}}-V r_{\mathrm{n}^{\prime}, \mathrm{t}}\right)-\mathrm{Yr}_{\mathrm{n}, \mathrm{n}^{\prime}} \cdot\left(V i_{\mathrm{n}, \mathrm{t}}-V i_{\mathrm{n}^{\prime}, \mathrm{t}}\right) \\
& \operatorname{IrS} q_{\mathrm{n}, \mathrm{n}^{\prime}, \mathrm{t}} \geq(\mathrm{v} \cdot \Delta \mathrm{Ir})^{2}+(2 \mathrm{v}-1) \cdot \Delta \mathrm{Ir} \cdot\left(\operatorname{Ir}_{\mathrm{n}, \mathrm{n}^{\prime}, \mathrm{v}, \mathrm{t}}-\mathrm{v} \cdot \Delta \mathrm{Ir}\right) ; \quad \mathrm{v} \in\{1, \ldots, \mathrm{Nv}\} \\
& \operatorname{IrS} q_{\mathrm{n}, \mathrm{n}^{\prime}, \mathrm{t}} \geq(\mathrm{v} \cdot \Delta \mathrm{Ir})^{2}-(2 \mathrm{v}-1) \cdot \Delta \mathrm{Ir} \cdot\left(\operatorname{Ir}_{\mathrm{n}, \mathrm{n}^{\prime}, \mathrm{v}, \mathrm{t}}+\mathrm{v} \cdot \Delta \mathrm{Ir}\right) ; \mathrm{v} \in\{1, \ldots, \mathrm{Nv}\} \\
& I i S q_{\mathrm{n}, \mathrm{n}^{\prime}, \mathrm{t}} \geq(\mathrm{v} \cdot \Delta \mathrm{Ii})^{2}+(2 \mathrm{v}-1) \cdot \Delta \mathrm{Ii} \cdot\left(I i_{\mathrm{n}, \mathrm{n}^{\prime}, \mathrm{v}, \mathrm{t}}-\mathrm{v} \cdot \Delta \mathrm{Ii}\right) ; \mathrm{v} \in\{1, \ldots, \mathrm{Nv}\} \\
& I i S q_{\mathrm{n}, \mathrm{n}^{\prime}, \mathrm{t}} \geq(\mathrm{v} \cdot \Delta \mathrm{Ii})^{2}-(2 \mathrm{v}-1) \cdot \Delta \mathrm{Ii} \cdot\left(I i_{\mathrm{n}, \mathrm{n}^{\prime}, \mathrm{v}, \mathrm{t}}+\mathrm{v} \cdot \Delta \mathrm{Ii}\right) ; \mathrm{v} \in\{1, \ldots, \mathrm{Nv}\} \\
& \Delta \mathrm{Ir}=\frac{\overline{\mathrm{Ir}}_{\mathrm{n}, \mathrm{n}^{\prime}}}{\mathrm{Nv}}, \Delta \mathrm{Ii}=\frac{\overline{\mathrm{I}}_{\mathrm{n}, \mathrm{n}^{\prime}}}{\mathrm{Nv}} \\
& \operatorname{IrS} q_{\mathrm{n}, \mathrm{n}^{\prime}, \mathrm{t}}+I i S q_{\mathrm{n}, \mathrm{n}^{\prime}, \mathrm{t}} \leq \overline{\mathrm{I}}_{\mathrm{n}, \mathrm{n}^{\prime}}^{2}
\end{aligned}
$$

It is worth noting that this approximation is always more than or equal to the exact square, i.e. $\operatorname{IrS} q \geq|I r|^{2}$ and $I i S q \geq|I i|^{2}$, making current magnitude and network losses larger than the exact values, resulting in a conservative solution. 


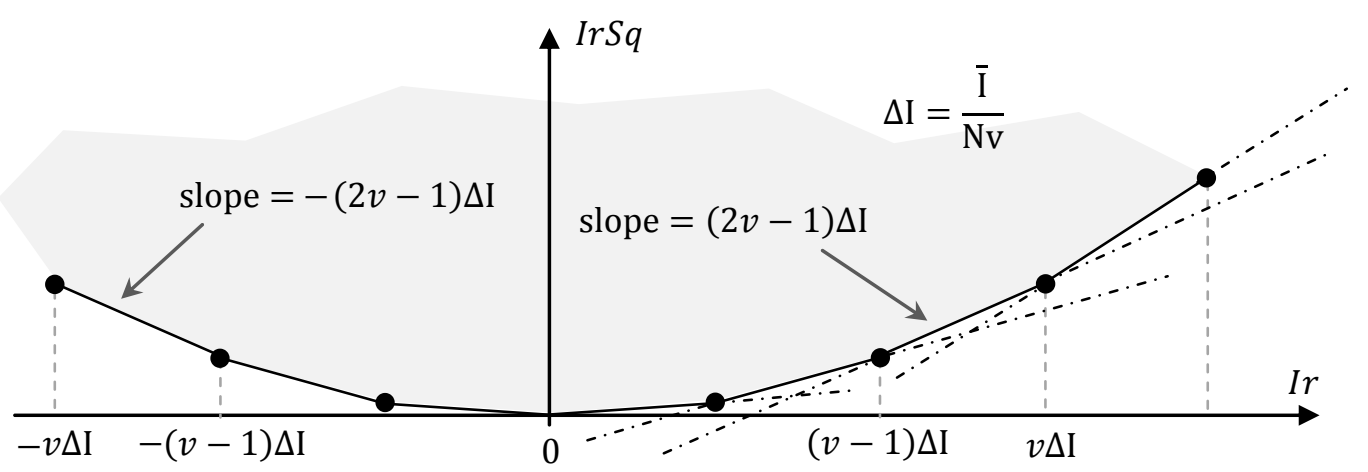

Figure 2 Piecewise linear approximation of current magnitude squared

\subsection{Bus Voltage Constraints}

Bus voltage magnitudes must remain within acceptable minimum and maximum thresholds, $\underline{V}$ and $\bar{V}$, or equivalently between arcs e and b-c shown in Figure 3. Such constraints, however, will be nonlinear when voltages are calculated in the Cartesian coordinates. To model these constraints in a linear approach, we enhanced an approach originally proposed in [38] by replacing the proposed less binding approximation with a more binding approximation (more conservative). Authors in [38] proposed to approximate the exact area (defined by edge a, arc b-c, edge d, and arc e) by the polyhedral area a-f-g-dh, using (21)-(24). In these equations, $\underline{\theta}$ and $\bar{\theta}$ are the minimum and maximum expected angles for bus voltages.

$$
\begin{gathered}
V i_{\mathrm{n}, \mathrm{t}} \leq \frac{\sin \bar{\theta}-\sin \underline{\theta}}{\cos \bar{\theta}-\cos \underline{\theta}}\left(V r_{\mathrm{n}, \mathrm{t}}-\underline{\mathrm{V}} \cdot \cos \underline{\theta}\right)+\underline{\mathrm{V}} \cdot \sin \underline{\theta} \\
V i_{\mathrm{n}, \mathrm{t}} \leq \frac{\sin \bar{\theta}}{\cos \bar{\theta}-1}\left(V r_{\mathrm{n}, \mathrm{t}}-\overline{\mathrm{V}}\right) \\
V i_{\mathrm{n}, \mathrm{t}} \leq \frac{-\sin \underline{\theta}}{\cos \underline{\theta}-1}\left(V r_{\mathrm{n}, \mathrm{t}}-\underline{\mathrm{V}}\right) \\
V r_{\mathrm{n}, \mathrm{t}} \cdot \tan \underline{\theta} \leq V i_{\mathrm{n}, \mathrm{t}} \leq V r_{\mathrm{n}, \mathrm{t}} \cdot \tan \bar{\theta}
\end{gathered}
$$

This approximation is conservative on the upper bound, and less binding on the lower bound of the voltage. That is because edges $f$ and $g$ are stricter than $\operatorname{arcs} b$ and $c$, but edge $h$ is relaxer than $\operatorname{arc} e$. Since under-voltage problems are more common in distribution networks than over-voltage problems, the less binding constraint on the lower bound may result in microgrid designs and DER placements that lead to under-voltage problems. In our formulation we alleviated this concern by substituting the less binding edge $\mathrm{h}$ with the more binding edge $\mathrm{h}^{\prime}$, through replacing $\underline{\mathrm{V}}$ with $\underline{\mathrm{V}}^{\prime}=\underline{\mathrm{V}} \cdot \sec \left(\frac{\bar{\theta}-\underline{\theta}}{2}\right)$, and rewriting (21) as (25). 


$$
V i_{\mathrm{n}, \mathrm{t}} \leq \frac{\sin \bar{\theta}-\sin \underline{\theta}}{\cos \bar{\theta}-\cos \underline{\theta}}\left(V r_{\mathrm{n}, \mathrm{t}}-\underline{\mathrm{V}} \cdot \sec \left(\frac{\bar{\theta}-\underline{\theta}}{2}\right) \cdot \cos \underline{\theta}\right)+\underline{\mathrm{V}} \cdot \sec \left(\frac{\bar{\theta}-\underline{\theta}}{2}\right) \cdot \sin \underline{\theta}
$$

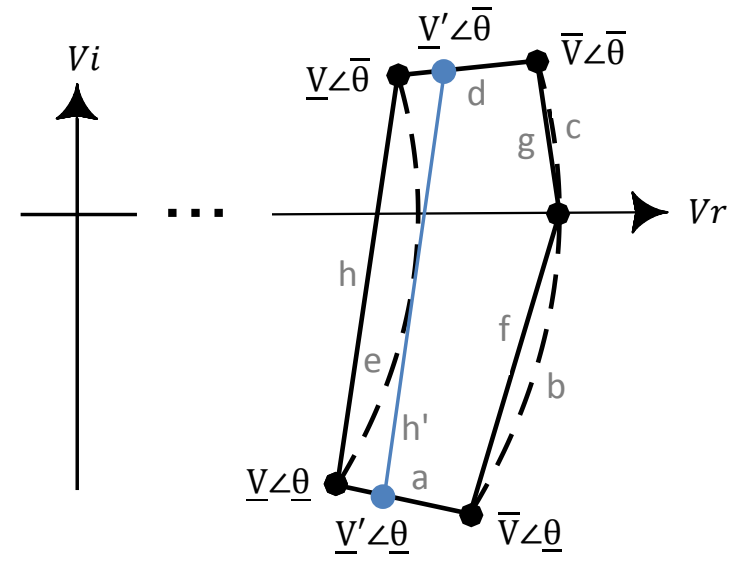

Figure 3 Conservative linear approximation of bus voltage magnitude constraints

\subsection{Heating Balance}

Equation (26) shows the heat balance at each node, accounting for heating loads and resources, heating needs of absorption chilling $\left(\frac{1}{\mathrm{COPa}} \cdot\right.$ Gen $\left._{\mathrm{n}, \mathrm{j}=\mathrm{AC}, \mathrm{t}}\right)$, heat recovered from $\mathrm{CHP}$ units, charging/discharging of heat storage technologies, and heat transfer between nodes (with linear approximation of network losses [28]) through the piping network. Equation (27) enforces the pipe capacities.

$$
\begin{aligned}
& \operatorname{Ld}_{\mathrm{n}, \mathrm{u}=\mathrm{HT}, \mathrm{t}}-L d C u r_{\mathrm{n}, \mathrm{u}=\mathrm{HT}, \mathrm{t}} \\
& +(1 / \mathrm{COPa}) \cdot \operatorname{Gen}_{\mathrm{n}, \mathrm{j}=\mathrm{AC}, \mathrm{t}}=\sum_{\mathrm{j} \in\{\mathrm{ST}, \mathrm{BL}\}} \operatorname{Gen}_{\mathrm{n}, \mathrm{j}, \mathrm{t}} \\
& +\sum_{\mathrm{g} \in\{\mathrm{ICE}, \mathrm{MT}\}} \alpha_{\mathrm{g}} \cdot \operatorname{Gen}_{\mathrm{n}, \mathrm{g}, \mathrm{t}} \\
& -\frac{1}{\operatorname{SCEff}_{\mathrm{s}=\mathrm{HS}}} \cdot \operatorname{SIn}_{\mathrm{n}, \mathrm{s}=\mathrm{HS}, \mathrm{t}}+\operatorname{SDEff}_{\mathrm{s}=\mathrm{HS}} \cdot \operatorname{SOut}_{\mathrm{n}, \mathrm{s}=\mathrm{HS}, \mathrm{t}} \\
& -\sum_{\mathrm{n}^{\prime}} \operatorname{HtTr}_{\mathrm{n}, \mathrm{n}^{\prime}, \mathrm{t}}+\sum_{\mathrm{n}^{\prime}}\left(1-\gamma_{\mathrm{n}, \mathrm{n}^{\prime}}\right) \cdot \operatorname{HtTr}_{\mathrm{n}^{\prime}, \mathrm{n}, \mathrm{t}} \\
& 0 \leq H t \operatorname{Hr}_{\mathrm{n}, \mathrm{n}^{\prime}, \mathrm{t}} \leq \overline{\operatorname{HtTr}}_{\mathrm{n}, \mathrm{n}^{\prime}}
\end{aligned}
$$

\subsection{Cooling Balance}

331 Equation (28) shows that the cooling load at each node can be met by a combination of electric and 332 absorption chilling and energy from cold storage technology. 


$$
\begin{aligned}
\operatorname{Ld}_{\mathrm{n}, \mathrm{u}=\mathrm{CL}, \mathrm{t}}-\operatorname{LdCur}_{\mathrm{n}, \mathrm{u}=\mathrm{CL}, \mathrm{t}} & =\sum_{\mathrm{c} \in\{\mathrm{AC}, \mathrm{EC}\}} \operatorname{Gen}_{\mathrm{n}, \mathrm{c}, \mathrm{t}} \\
& +\operatorname{SDEff}_{\mathrm{s}=\mathrm{CS}} \cdot \operatorname{SOut}_{\mathrm{n}, \mathrm{s}=\mathrm{CS}, \mathrm{t}}-\frac{1}{\operatorname{SCEff}_{\mathrm{s}=\mathrm{CS}}} \cdot \operatorname{SIn}_{\mathrm{n}, \mathrm{s}=\mathrm{CS}, \mathrm{t}}
\end{aligned}
$$

333

334

335

336

\subsection{Storage Constraints}

Equation (29) tracks the state of charge (SOC) for electrical, heat, and cold storage technologies, and considers self-discharge. Equation (30) keeps the SOC within its limits and (31) sets rate limits on charging and discharging.

$$
\begin{gathered}
S O C_{\mathrm{n}, \mathrm{s}, \mathrm{t}}=\left(1-\phi_{s}\right) \cdot S O C_{\mathrm{n}, \mathrm{s}, \mathrm{t}-1}+\operatorname{SIn}_{\mathrm{n}, \mathrm{s}, \mathrm{t}}-\operatorname{SOut}_{\mathrm{n}, \mathrm{s}, \mathrm{t}} \\
\underline{\mathrm{SOC}}_{\mathrm{s}} \leq S O u t_{\mathrm{n}, \mathrm{s}, \mathrm{t}} \leq \overline{\mathrm{SOC}}_{\mathrm{s}} \\
\operatorname{SIn}_{\mathrm{n}, \mathrm{s}, \mathrm{t}} \leq \operatorname{Cap}_{\mathrm{n}, \mathrm{s}} \cdot \overline{\mathrm{SCRt}}_{\mathrm{s}}, \quad \operatorname{SOut}_{\mathrm{n}, \mathrm{s}, \mathrm{t}} \leq \operatorname{Cap}_{\mathrm{n}, \mathrm{s}} \cdot \overline{\operatorname{SDRt}}_{\mathrm{s}}
\end{gathered}
$$

\section{$337 \quad 3.11$ Generation Constraints}

338 Equations (32)-(34) ensure that the dispatch of each technology does not exceed its maximum capacity 339 or potential. Equation (32) limits the generation of PV and solar-thermal technologies at each time 340 based on the available solar energy at the time. Equations (33)-(35) relate the operating power and 341 capacity for continuous and discrete technologies. The $M$ in (34) denotes a very large number.

$$
\begin{gathered}
\operatorname{Gen}_{\mathrm{n}, \mathrm{c}, \mathrm{t}} \leq \operatorname{Cap}_{\mathrm{n}, \mathrm{c}} \cdot \frac{\operatorname{SolEff}_{\mathrm{c}, \mathrm{t}}}{\operatorname{ScPkEff}_{\mathrm{c}}} \cdot \operatorname{Solar}_{\mathrm{t}} ; \mathrm{c} \in\{\mathrm{PV}, \mathrm{ST}\} \\
\operatorname{Gen}_{\mathrm{n}, \mathrm{g}, \mathrm{t}} \leq \operatorname{inv}_{\mathrm{n}, \mathrm{g}} \cdot \overline{\operatorname{DERP}}_{\mathrm{g}} \\
\operatorname{Cap}_{\mathrm{n}, \mathrm{t}} \leq \operatorname{pur}_{\mathrm{n}, \mathrm{k}} \cdot \mathrm{M} \\
\operatorname{Gen}_{\mathrm{n}, \mathrm{c}, \mathrm{t}} \leq \operatorname{Cap}_{\mathrm{n}, \mathrm{c}}
\end{gathered}
$$

\subsection{Import and Export Constraints}

343 Equations (36)-(38) prevent simultaneous import and export to/from the grid and also set the maximum 344 allowable export. Note that if a grid connection does not exist, i.e. parameter grd = 0, both $U t P u r_{n, t}$ 345 and $U t E x p_{n, t}$ will be fixed at zero.

$$
\begin{gathered}
U t P u r_{\mathrm{n}, \mathrm{t}} \leq p s b_{\mathrm{n}, \mathrm{t}} \cdot \operatorname{grd} \cdot \mathrm{M} ; \mathrm{n}=\mathrm{N} \\
U t \operatorname{Exp}_{\mathrm{n}, \mathrm{t}} \leq\left(1-p s b_{\mathrm{n}, \mathrm{t}}\right) \cdot \operatorname{grd} \cdot \overline{\mathrm{UtExp}} ; \mathrm{n}=\mathrm{N} \\
U t P u r_{\mathrm{n}, \mathrm{t}}=0, \quad U t \operatorname{Exp}_{\mathrm{n}, \mathrm{t}}=0 ; \mathrm{n} \neq \mathrm{N}
\end{gathered}
$$




\section{Case Study}

\section{$347 \quad 4.1$ Case Setup and Input Data}

348 The arbitrary $12 \mathrm{kV}$ microgrid shown in Figure 4 was used as an example. This microgrid is composed of 3495 nodes and 4 buildings. Typical building load profiles were generated based on commercial building 350 databases [39] with annual electrical, heating, and cooling loads listed in Table 2. For the electrical 351 network, a cable with an impedance of $(64+i 1.4) \times 10^{-6} \mathrm{pu} / \mathrm{m}$ and ampacity of 0.4 pu was arbitrarily 352 considered. For the heating network, pipes with thermal loss coefficient of $\gamma=4 \times 10^{-5} \% / \mathrm{m}$ and 353 capacity of $3000 \mathrm{~kW}$-th were considered. Investments in PV, battery, CHP-enabled Internal Combustion 354 Engine (ICE), absorption chiller, gas-fired boiler, and electric chiller were allowed (characteristics in Table 3553 and Table 4).

356

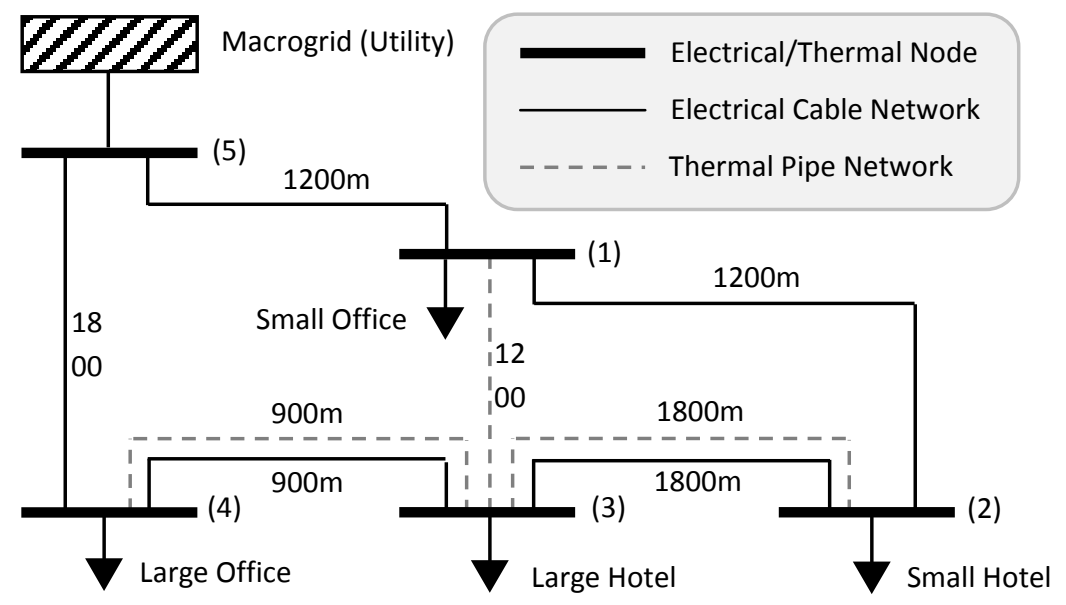

Figure 4 Electrical and thermal networks for the example 5-node microgrid

Table 2 Building annual electrical, cooling, and heating loads

\begin{tabular}{lllllll}
\hline & \multicolumn{2}{l}{ Annual Electrical Load } & \multicolumn{2}{l}{ Annual Cooling Load } & \multicolumn{2}{l}{ Annual Heating Load } \\
\cline { 2 - 7 } Node & $\begin{array}{l}\text { Energy } \\
(\mathrm{MWh})\end{array}$ & $\begin{array}{l}\text { Max Power } \\
(\mathrm{kW})\end{array}$ & $\begin{array}{l}\text { Energy } \\
(\text { MWh th) }\end{array}$ & $\begin{array}{l}\text { Max Power } \\
(\mathrm{kW} \mathrm{th)}\end{array}$ & $\begin{array}{l}\text { Energy } \\
\text { (MWh th) }\end{array}$ & $\begin{array}{l}\text { Max Power } \\
(\mathrm{kW} \text { th) }\end{array}$ \\
\hline \hline 1 & 1,467 & 424 & 450 & 1,242 & 1,160 & 3,282 \\
\hline 2 & 3,181 & 636 & 3,204 & 1,710 & 4,014 & 1,196 \\
\hline 3 & 4,059 & 939 & 29,295 & 4,865 & 10,897 & 3,379 \\
\hline 4 & 3,341 & 1,012 & 4,631 & 2,403 & 1,459 & 4,779 \\
\hline \hline Aggregate & 12,048 & 2,318 & 37,575 & 9,743 & 17,530 & 12,079 \\
\hline
\end{tabular}

Table 3 Discrete technology option characteristics

\begin{tabular}{llllll}
\hline & $\begin{array}{l}\text { Capacity } \\
(\mathrm{kW})\end{array}$ & $\begin{array}{l}\text { Lifetime } \\
\text { (years) }\end{array}$ & $\begin{array}{l}\text { Capital Cost } \\
(\$ / \mathrm{kW})\end{array}$ & $\begin{array}{l}\text { Efficiency } \\
(\%)\end{array}$ & $\begin{array}{l}\text { Heat Recovery } \\
(\mathrm{kW} / \mathrm{kW})\end{array}$ \\
\hline \hline ICE-1 & 1,000 & 20 & 4,969 & 0.368 & 1.019 \\
\hline ICE-2 & 2,500 & 20 & 4,223 & 0.404 & 0.786 \\
\hline ICE-3 & 5,000 & 20 & 3,074 & 0.416 & 0.797 \\
\hline
\end{tabular}


Table 4 Continuous technology option characteristics

\begin{tabular}{llll}
\hline Technology & $\begin{array}{l}\text { Fixed Cost } \\
(\$)\end{array}$ & $\begin{array}{l}\text { Variable Cost } \\
(\$ / \mathrm{kW} \text { or } \$ / \mathrm{kWh})\end{array}$ & $\begin{array}{l}\text { Lifetime } \\
\text { (years) }\end{array}$ \\
\hline \hline Battery & 500 & 500 & 5 \\
\hline PV & 2,500 & 2,500 & 30 \\
\hline Gas Boiler & 6,000 & 45 & 10 \\
\hline Electric Chiller & 2,300 & 230 & 10 \\
\hline Absorption Chiller & 250 & 250 & 20 \\
\hline
\end{tabular}

Two cases were studied:

- Case I (single-node): Building loads were aggregated and electrical and thermal networks were not considered, resulting in a single-node aggregate approach. The DER portfolio and sizes (at the microgrid level) were obtained using the aggregate approach.

- Case II (multi-node): The multi-node optimization formulation presented in the paper was used and the electrical and thermal networks introduced above were considered. The optimal technology portfolio, DER places, and DER sizes were determined.

The results of the two case studies are used to explore how investment options can be different between single-node and multi-node modeling for the same design problem, and hence, demonstrate the importance of the multi-node modeling (with the ability for optimal DER placement) for multienergy microgrids. To achieve reliable solutions, the optimization precision (stopping criterion) was set to $0.05 \%$ in these studies.

\subsection{Optimal Technology Portfolio and Placement}

The case study results are reported in Figure 5, Table 5, and Table 6. Figure 5 shows the optimal capacity and placement of various technologies. For each of the two cases, Figure 5 shows the optimal DER and HVAC technology portfolio and capacities. In the single-node approach in case I, technology capacities for nodes 1-5 are not applicable and only the aggregate capacities are relevant. On the contrary in the multi-node study of case II, technology capacities are optimally determined for each node (building). In case II, the solution does not include any investment in node 5 , and hence, node 5 is not shown in this figure. The percentages shown on the bars compare the summation of nodal capacities in case II with the aggregate capacity in case I. As an example, it can be seen that a 1,330 kW absorption chiller is installed in case I for the microgrid. In case II, four absorption chillers with 262, 246, 457, and $497 \mathrm{~kW}$ capacities are installed at nodes 1-4, respectively. These numbers add up to a total of 1,462 kW, which is $10 \%$ more than the $1,330 \mathrm{~kW}$ capacity from case I.

Table 5 shows the annual investment and operation costs for the two cases, where total annual cost is the optimization objective. The percentages for case II costs refer to case I. Table 6 shows the capacity factor for the operation of various technologies in case I and case II. The capacity factors are used to draw some conclusions in the following paragraphs. 


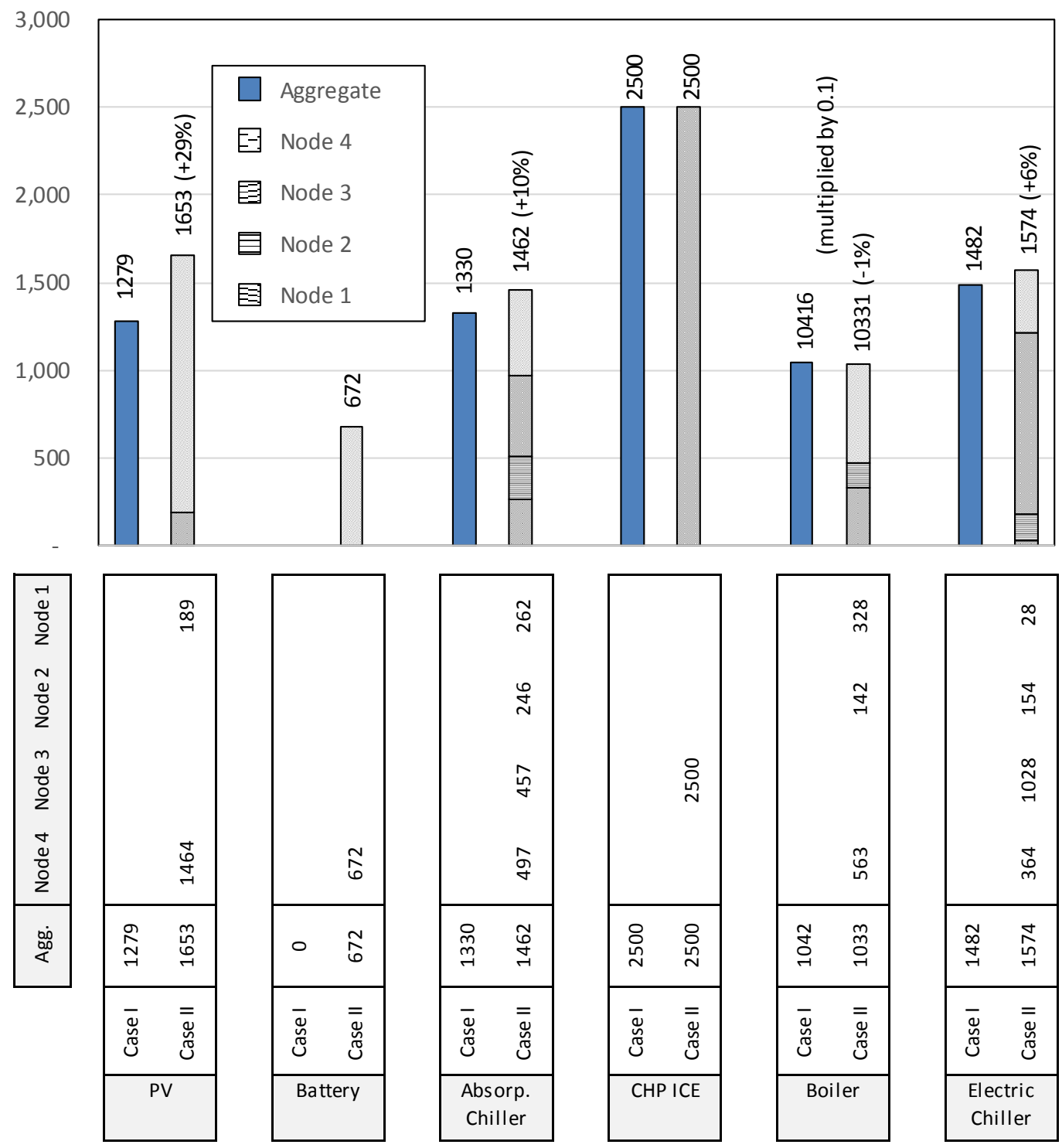

Figure 5 Case study results - optimal technology portfolio, placement, and sizes

Table 5 Case study results - annual investment and operation costs

\begin{tabular}{llll}
\hline Case No & Annualized Investment Cost $(\mathrm{k} \$)$ & Annual Operation Cost $(\mathrm{k} \$)$ & Total Annual Cost (k\$) \\
\hline \hline Case I (Single-node) & 1,055 & 1,561 & 2,616 \\
\hline Case II (Multi-node) & $1,182(+12.1 \%)$ & $1,572(+0.6 \%)$ & $2,754(+5.3 \%)$ \\
\hline
\end{tabular}


Table 6 Case study results - operation capacity factors for various technologies

\begin{tabular}{|c|c|c|c|c|c|c|}
\hline \multirow[b]{2}{*}{ Technology } & \multirow{2}{*}{$\begin{array}{l}\text { Case I (Single-node) } \\
\text { Aggregate }\end{array}$} & \multicolumn{5}{|c|}{ Case II (Multi-node) } \\
\hline & & Node 1 & Node 2 & Node 3 & Node 4 & Aggregate \\
\hline $\mathrm{CHP}$ & $74.5 \%$ & - & - & $73.2 \%$ & - & $73.2 \%$ \\
\hline Absorption Chiller & $11.9 \%$ & $2.6 \%$ & $10.2 \%$ & $4.9 \%$ & $8.9 \%$ & $6.7 \%$ \\
\hline Electric Chiller & $53.5 \%$ & $16.9 \%$ & $36.4 \%$ & $70.0 \%$ & $20.0 \%$ & $54.2 \%$ \\
\hline Gas Boiler & $14.9 \%$ & $4.3 \%$ & $34.1 \%$ & - & $10.2 \%$ & $11.6 \%$ \\
\hline
\end{tabular}

By comparing case I and II, we can make several observations:

- Not only the aggregate technology capacities are different between the two cases, the technology portfolio is also not the same, as the portfolio in case II (multi-node modeling) includes a battery and the portfolio in case I (single-node modeling) does not. This makes the case for the importance of the proposed multi-node modeling approach as opposed to commonly used single-node aggregate approaches.

- In both cases a 2,500 kW CHP unit is installed and the aggregate boiler capacity remains almost constant from case I to case II. However, the aggregate capacity of PV, battery, absorption chiller, and electric chiller increases from case I to case II.

- Although the CHP capacity is the same between the two cases, network constraints in case II limit the generation of the CHP unit. As a consequence, the capacity factor of the CHP unit drops from $74.5 \%$ in case I to $73.2 \%$ in case II.

- In case II with the optimal DER placement capability, the CHP unit is installed at node 3 (large hotel), which has the highest electrical/cooling/heating load among the four buildings.

- Although there is no battery in case I, a $672 \mathrm{kWh}$ battery is installed at node 4 in case II. After node 3 (in which the CHP unit is installed), node 4 has the highest electrical load among the four buildings. In this example, the battery is typically used during morning and afternoon peaks to reduce electricity purchase from the utility during these hours (it will be shown in section 4.3).

- The absorption cooling becomes less attractive in case II, where network constraints are considered. Instead, the amount of electric cooling increases, followed by a higher overall installed electric chiller capacity in case II. It is worth noting that although the total amount of cooling met by absorption decreases in case II, the installed capacity for absorption chillers increases. This seemingly contradicting result is a reflection of the load aggregation used in case I. Namely, the absorption cooler in the single-node formulation is sized based on the maximum overall (aggregated) absorption cooling load (in kW), which is not necessarily the same as individually sizing absorption chillers based on the loads in each of the nodes. Hence, the total absorption chiller size of all 4 nodes in case II exceeds the installed capacity in case I, even though the effective amount of cooling met through absorption chillers is lower. This is confirmed by analyzing the capacity factor for the absorption coolers in the system, which decreases from $11.9 \%$ in case I to $6.7 \%$ in case II.

- As a result of the lower use of absorption chillers, the total heating load, which includes heat used to drive these chillers, is smaller in case II than in case I. However, the same observation is made regarding total installed capacity, as the boiler at each node is sized based on the 
maximum heating load at that node, and this results in a total capacity which exceeds the maximum of the aggregate load in the single-node formulation, even though the boilers are used less often. Once again, this is confirmed by analyzing the aggregate capacity factor of boilers, which decreases from $14.9 \%$ in case I to $11.6 \%$ in case II.

- The investment cost in case II is $12.1 \%$ higher due to installing more DERs in the microgrid.

- The $0.6 \%$ increase in the annual operation cost is the aggregate outcome of several conflicting changes from case I to case II, including more electricity purchase from the utility, more onsite PV generation, and less fuel consumption. Also in contrast with case I, the network electrical and thermal losses are modeled in case II.

- The total annual investment and operation cost in this example increases by $5.3 \%$ when electrical and thermal network constraints are taken into account. It indicates that single-node aggregate approaches may under-estimate investment capacities and annual costs. We have conducted further studies that showed the under-estimation gap increases as the network weakens (higher line impedances and lower line ampacities). Another problem with aggregate approaches, as discussed earlier in the paper, is that they are inherently unable to perform optimal DER placement.

\subsection{Optimal Electrical, Cooling, and Heating Dispatch}

Figure 6 shows the optimal electrical dispatch for nodes 1-5 in case II during a typical week day in August (month and day-type arbitrarily chosen). For each node the demand is composed of the node electrical load, consumption of the electric chiller at the node, and the electrical power being exported to other nodes. The supply includes PV generation at the node, ICE generation at the node, discharge of the battery at the node, electricity purchased from the grid at the node, and electrical power being imported from other nodes. In node 4 when the supply exceeds the demand, excess energy is stored in the battery. The battery state of charge can be seen on the second axis.

Node 5 is the point of common coupling to the utility grid and does not have any loads. It can be observed that the microgrid only purchases electricity from the grid during morning and afternoon load peaks, i.e. 7-10am and 7-9pm. It can also be observed that the electricity purchase from the grid has an almost flat profile during these hours in order to minimize incurred demand charges. As explained in section 3.5, an approximation of the entire microgrid power loss is modeled at the slack bus in our formulation (bus 5 in this example). The excess supply power seen in this node is to compensate network losses.

It can be observed that the CHP unit in node 3 runs continuously and exports its excess power to other nodes. Nodes 1, 2, and 4 are importer nodes and never have extra supply to export. The dispatch at node 4 shows that the battery is used during morning and afternoon load peak hours. The battery helps to reduce electricity purchase from the grid and also to keep a flat purchase profile during these hours.

Figure 7 shows the optimal heating dispatch for nodes 1-4 in case II for the same month and day-type. Node 5 is not shown since it does not have any heating loads or resources. The demand at each node is composed of water/space heating load, heating load of absorption cooling, and heat export to other nodes. The node supply entails heat provided by the boiler at the node, heat recovered from $\mathrm{CHP}$ at the 
node, and imported heat from other microgrid nodes. It can be observed that node 3 is a heat exporter node and transfers its excess recovered heat to other nodes. Nodes 1 and 2 are heat importers and use

470 the imported heat along with their boilers to meet their demands. Node 4 imports heat from node 3

471 from 9am to $5 \mathrm{pm}$ and exports to node 3 before 9 am and after $5 \mathrm{pm}$.

472 Figure 8 shows the optimal cooling dispatch for nodes 1-4 in case II for the same month and day-type. It 473 can be seen that the cooling load at each node is met by a combination of electric and absorption cooling at the node. Since node 3 has a CHP unit, one may expect the cooling load in this node to be met 475 mostly by absorption cooling. However, the dispatch in this figure shows that this node has the lowest 476 absorption to electric cooling ratio among the four nodes. That is because the electrical network 477 capacity is fairly limited, while the piping network has a high capacity. As a result, the electrical 478 generation of the CHP unit is used locally to supply the electrical loads (including electric chiller) and 479 most of the recovered heat is exported to other nodes for their heating and absorption cooling loads.

480 Figure 9 shows the optimal electrical, heating, and cooling dispatch for the microgrid in case I for the 481 same month and day-type, i.e. a typical weekday in August. The aggregate modeling is not able to 482 capture the microgrid's internal energy transfer. It is also unable to determine the dispatch at the node 483 level. To further demonstrate the optimal dispatch differences between single-node and multi-node 484 modeling, Figure 10 compares the (aggregate) optimal dispatch between case I (single node) and case II 485 (multi-node). In case I, system loads are met by PV and CHP technologies. On the contrary in case II 486 loads are served by PV, CHP, utility electricity, and battery. It can be observed that the electric chiller 487 loads are also different between the two cases, which is because of the different absorption and electric 488 chiller sizes. 

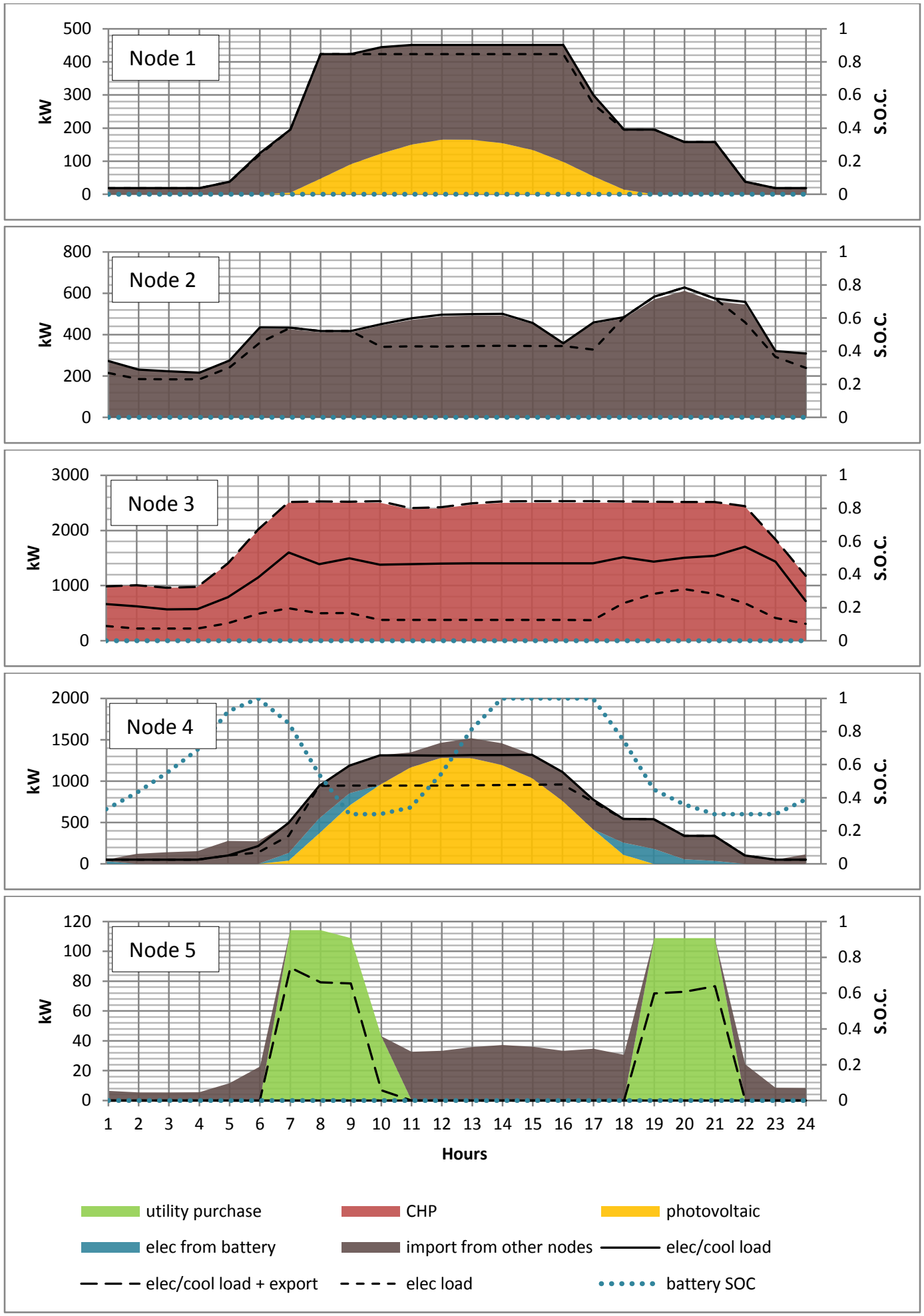

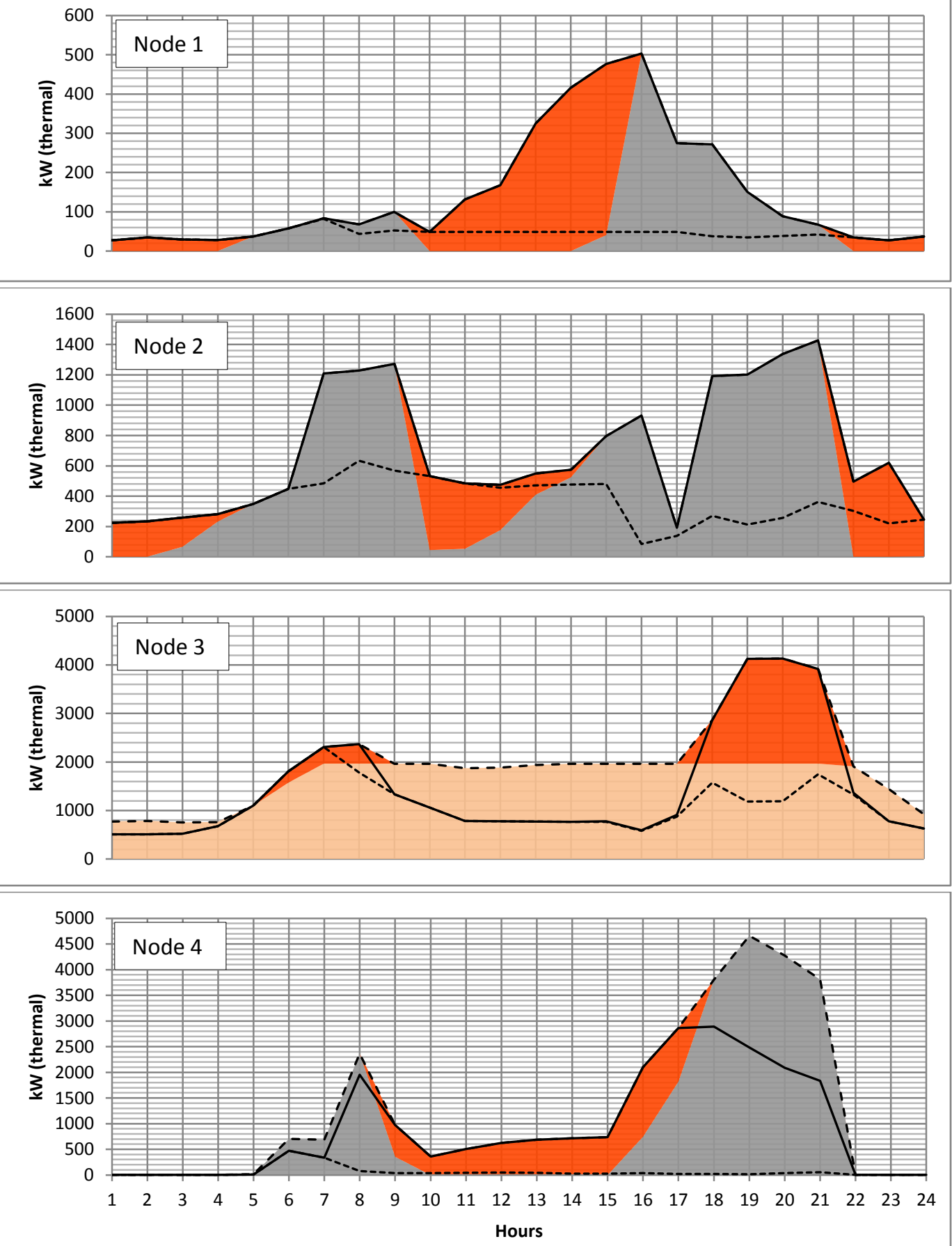

heat import from other nodes

heat load

heat + absorp load

- - - - heat + absorp load + export 

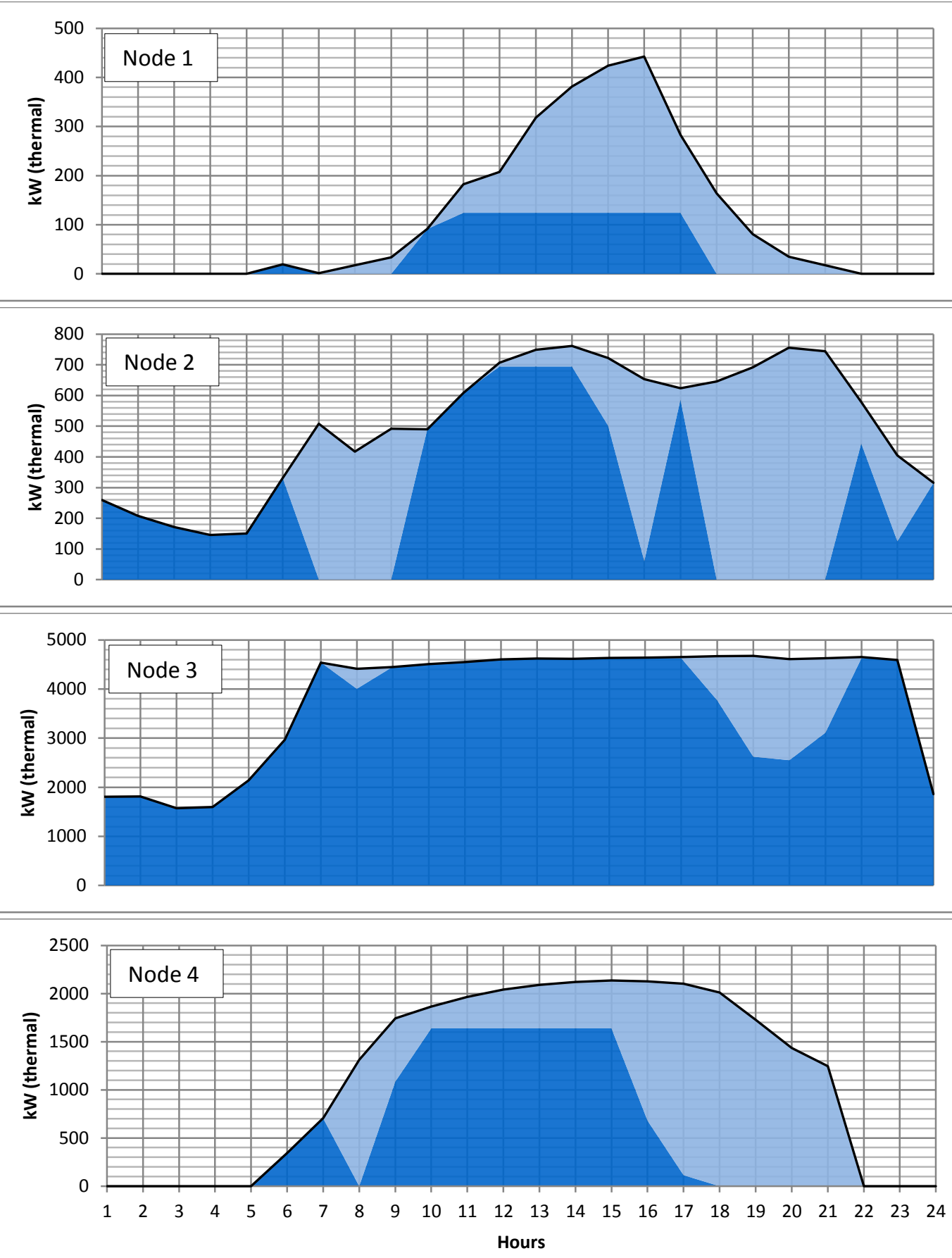

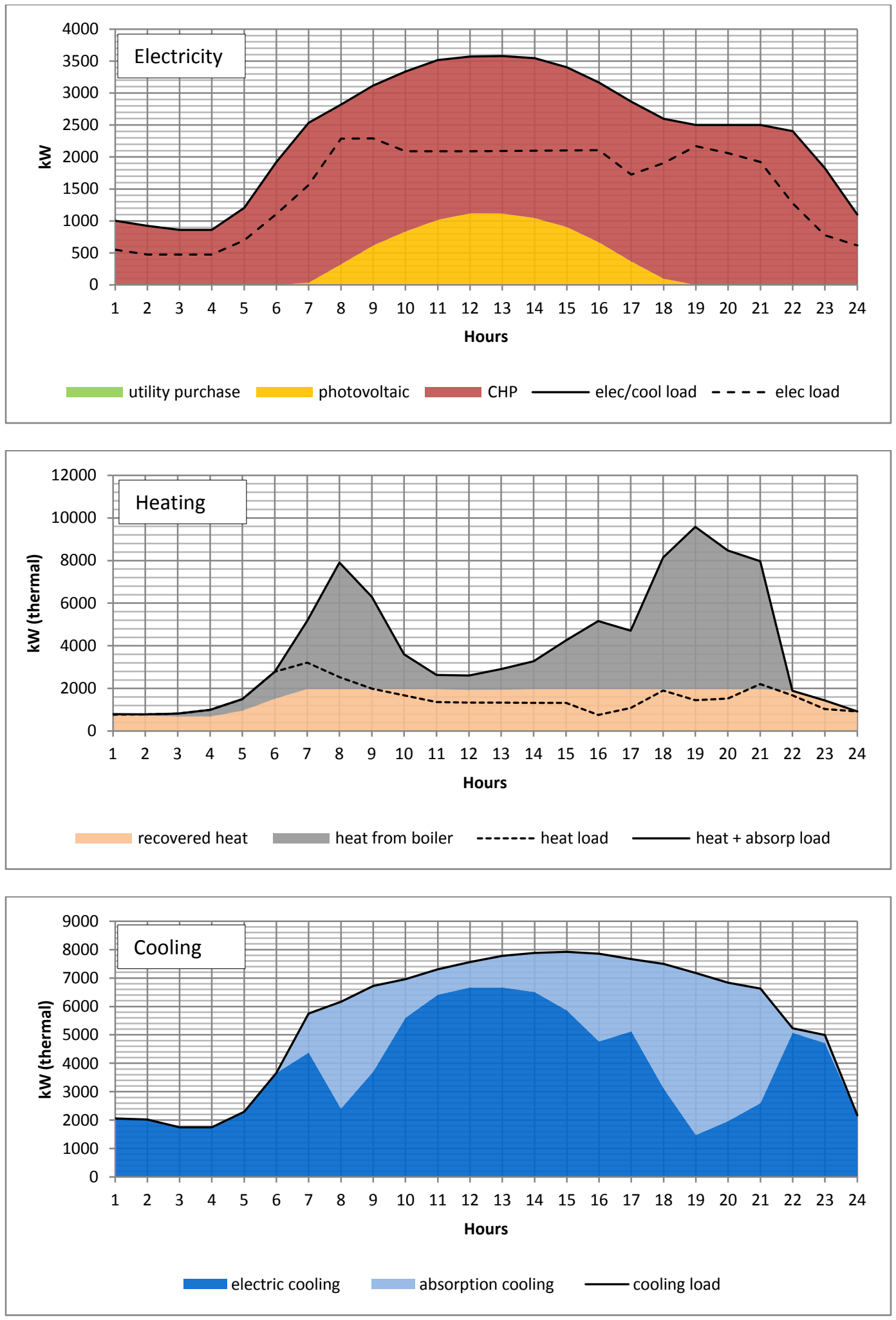

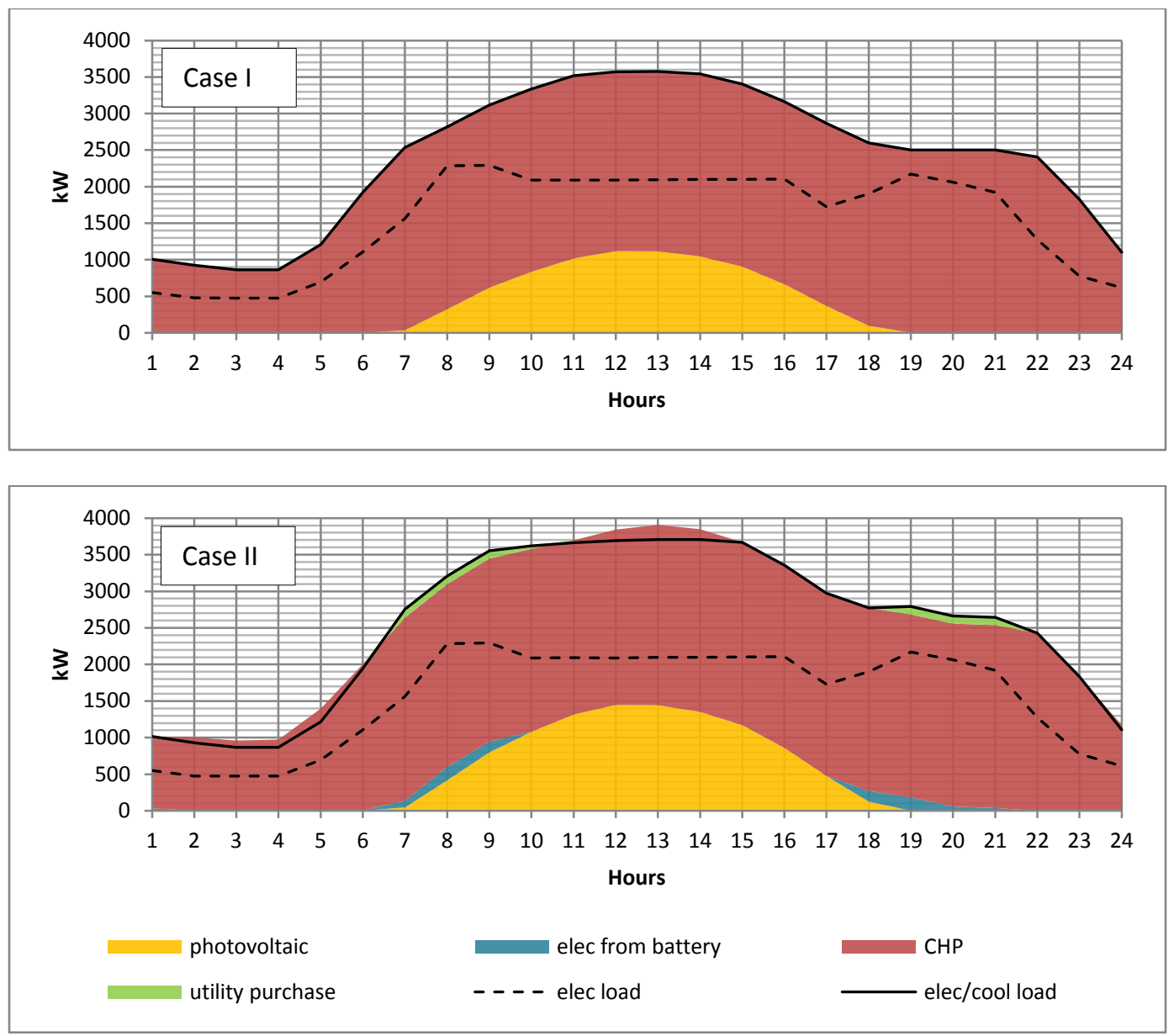

512 Figure 10 Case study results - comparison of aggregate electricity dispatch between case I and II (a typical weekday in August)

\subsection{Accuracy of the Approximate Power Flow Solution}

514 In our formulation, a linear approximation of power flow equations is used. Figure 11 shows the 515 histogram and cumulative distribution function (CDF) for the errors in bus voltage magnitudes in case II. 516 To generate this plot, the exact power flow solution (Newton-Raphson method) was calculated for the 517 network at each time step using the optimal dispatch (output from the optimization), and the exact 518 power flow solution was compared with the approximation (from within the optimization) for all the 519 data points. It can be observed that the errors are very small and $97 \%$ of the voltage data points have an 520 error less than $0.25 \%$. Figure 12 shows the voltage variation (over a year) at each node for both exact 521 and approximate power flow solutions. It can be observed that the ranges are very close. Also, the 522 voltage never drops below the minimum acceptable threshold of $0.9 \mathrm{pu}$. 


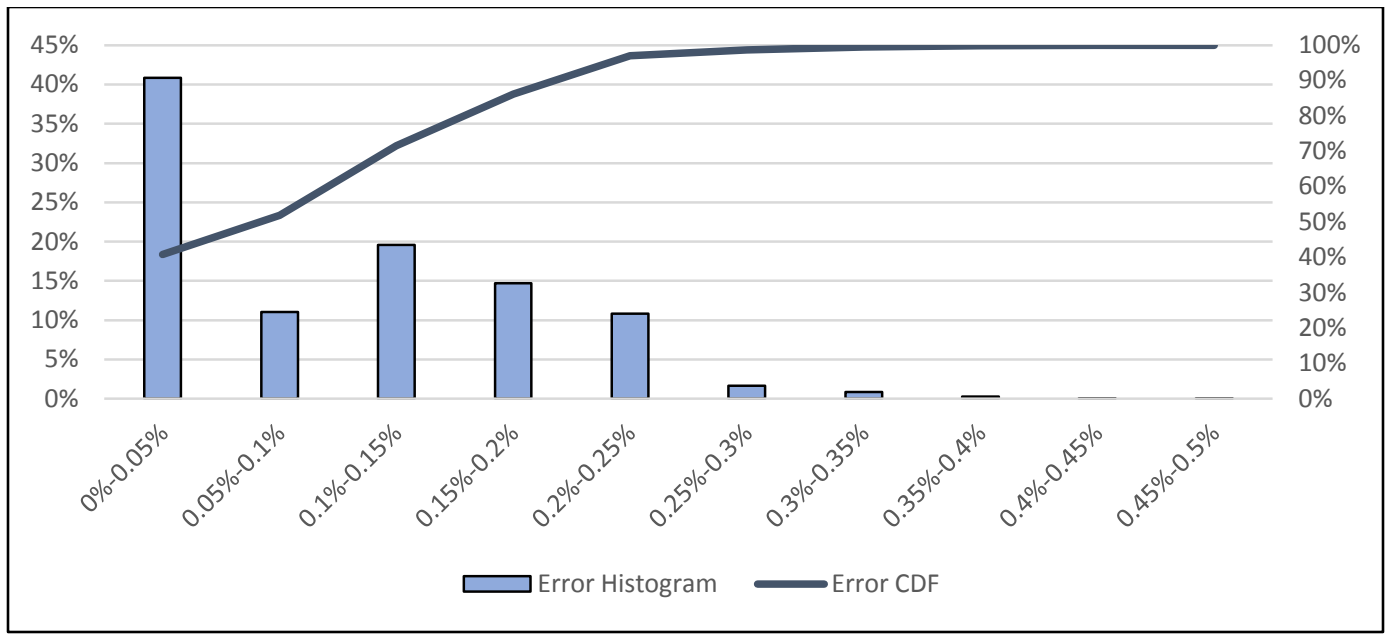

Figure 11 Case study results - accuracy of the approximate power flow solution

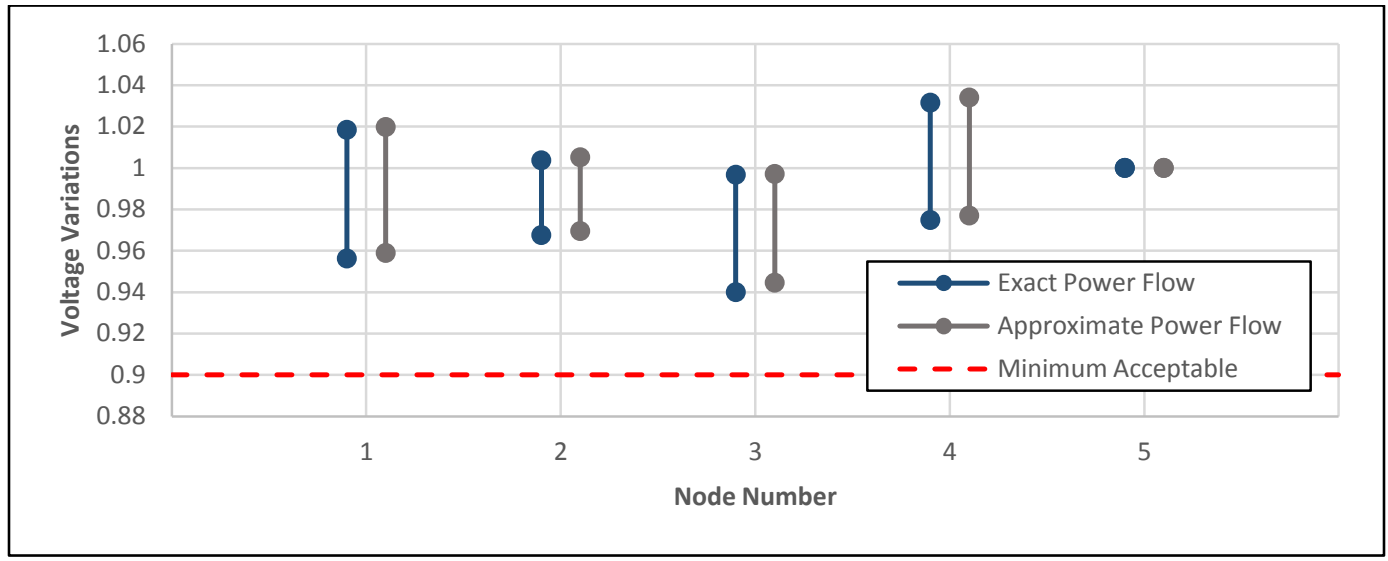

Figure 12 Case study results - voltage magnitude variations at each node

\subsection{Verification of the "Approximate Power Flow Existence Condition"}

As discussed in section 3.5, the network needs to meet the "approximate power flow existence condition" for the power flow equations to be valid. It was explained that this condition can be verified using two methods:

- Method one, post-optimization: The $\left\|\boldsymbol{s}_{\mathrm{t}}\right\|$ calculated from the optimization results ranges between 0.32506 and 1.4087. All of the $\left\|\boldsymbol{s}_{\mathrm{t}}\right\|$ in this range satisfy the "approximate power flow existence conation".

- Method two, pre-optimization: For the example microgrid, the sufficient condition of (9) for the pre-optimization verification of the power flow model holds true, since

$$
\sqrt{\sum_{\mathrm{n} \neq \mathrm{N}}\left(\sum_{\mathrm{n} \prime} \overline{\mathrm{S}}_{\mathrm{n}, \mathrm{n}^{\prime}}\right)^{2}}=\sqrt{4 \times(0.4+0.4)^{2}}=1.6 \leq \frac{1}{4 \cdot\|\mathrm{Z}\|^{*}} \cdot \mathrm{V}_{0}^{2}=\frac{1}{4 \times 0.13}=1.92
$$




\section{Conclusions and Future Work}

This paper presented a mixed-integer linear programming model for optimal microgrid design, including optimal technology portfolio, placement, and dispatch, for multi-energy microgrids, i.e. microgrids with electricity, heating, and cooling loads and resources. To optimally place DERs in the microgrid, our optimization formulation includes integer linear models for electricity and heat transfer networks, as well as their physical and operational constraints.

To illustrate how the developed optimization model works, we conducted a case study in which we solved the optimal microgrid design problem for an example microgrid using both a single-node aggregate approach (and hence without DER placement) and our proposed multi-node approach (with DER placement). The results indicated that aggregate approaches are inherently incapable of DER placement in the microgrid. Moreover, they may result in non-optimal technology portfolio and underestimation of DER capacities, since they cannot capture the internal energy transfer within the microgrid and the limitations of the electrical/thermal networks. For the example microgrid studied, we also compared our approximate power flow solution with the exact power flow solution and observed very small errors in bus voltage magnitudes.

Further research work will focus on modeling of larger microgrids with more nodes and studying its impact on the solution time. Integrating alternative linear power flow models will also be pursued. Furthermore, research will be carried out on the inclusion of network design (cable connections and types), as well as N-1 security constraints, and evaluating their impact on the technology portfolio and investment cost.

\section{Acknowledgment}

The authors gratefully thank Dan T. Ton, the Smart Grid R\&D Program Manager at the US Department of Energy, for his continuous support of the microgrid design tools at LBNL.

\section{References}

[1] "About the Initiative," New York State Department of Public Service, 2015. [Online]. Available: www.dps.ny.gov/REV/.

[2] C. Marnay, F. J. Robio, and A. S. Siddiqui, "Shape of the microgrid," in Proc. 2001 IEEE Power Engineering Society Winter Meeting, pp. 150-153, 2001.

[3] M. Stadler, G. Cardoso, S. Mashayekh, T. Forget, N. DeForest, A. Agarwal, and A. Schönbein, "Value streams in microgrids: A literature review," Applied Energy, vol. 162, pp. 980-989, 2016.

[4] C. Brandoni and M. Renzi, "Optimal sizing of hybrid solar micro-CHP systems for the household sector," Applied Thermal Engineering, vol. 75, pp. 896-907, 2015.

[5] M. Motevasel, A. R. Seifi, and T. Niknam, "Multi-objective energy management of CHP (combined heat and power)-based micro-grid," Energy, vol. 51, pp. 123-136, 2013.

[6] P. Mancarella, "MES (multi-energy systems): An overview of concepts and evaluation models," Energy, vol. 65, pp. 1-17, 2/1/ 2014.

[7] D. Connolly, H. Lund, B. V. Mathiesen, and M. Leahy, "A review of computer tools for analysing the integration of renewable energy into various energy systems," Applied Energy, vol. 87, pp. 1059-1082, 2010. 
575 [8] G. Mendes, C. loakimidis, and P. Ferrão, "On the planning and analysis of Integrated Community Energy Systems: A review and survey of available tools," Renewable and Sustainable Energy Reviews, vol. 15, pp. 4836-4854, 2011.

[9] Z. Huang, H. Yu, Z. Peng, and M. Zhao, "Methods and tools for community energy planning: A

[10] C. Gamarra and J. M. Guerrero, "Computational optimization techniques applied to microgrids planning: A review," Renewable and Sustainable Energy Reviews, vol. 48, pp. 413-424, 2015.

[11] A. H. Fathima and K. Palanisamy, "Optimization in microgrids with hybrid energy systems - A review," Renewable and Sustainable Energy Reviews, vol. 45, pp. 431-446, 5// 2015.

[12] A. Ahmad Khan, M. Naeem, M. Iqbal, S. Qaisar, and A. Anpalagan, "A compendium of optimization objectives, constraints, tools and algorithms for energy management in microgrids," Renewable and Sustainable Energy Reviews, vol. 58, pp. 1664-1683, 5// 2016.

[13] W.-S. Tan, M. Y. Hassan, M. S. Majid, and H. Abdul Rahman, "Optimal distributed renewable generation planning: A review of different approaches," Renewable and Sustainable Energy Reviews, vol. 18, pp. 626-645, 2013.

[14] D. Singh, D. Singh, and K. S. Verma, "Multiobjective Optimization for DG Planning With Load Models," IEEE Transactions on Power Systems, vol. 24, pp. 427-436, 2009.

[15] C. L. T. Borges and D. M. Falcão, "Optimal distributed generation allocation for reliability, losses, and voltage improvement," International Journal of Electrical Power \& Energy Systems, vol. 28, pp. 413-420, 2006.

594

595

[16] B. Kroposki, P. K. Sen, and K. Malmedal, "Optimum Sizing and Placement of Distributed and Renewable Energy Sources in Electric Power Distribution Systems," IEEE Transactions on Industry Applications, vol. 49, pp. 2741-2752, 2013.

[17] J.-H. Teng, Y.-H. Liu, C.-Y. Chen, and C.-F. Chen, "Value-based distributed generator placements for service quality improvements," International Journal of Electrical Power \& Energy Systems, vol. 29, pp. 268-274, 2007.

[18] W. Zhaoyu, C. Bokan, W. Jianhui, K. Jinho, and M. M. Begovic, "Robust Optimization Based Optimal DG Placement in Microgrids," IEEE Transactions on Smart Grid, vol. 5, pp. 2173-2182, 2014.

[19] D. Buoro, M. Casisi, A. De Nardi, P. Pinamonti, and M. Reini, "Multicriteria optimization of a distributed energy supply system for an industrial area," Energy, vol. 58, pp. 128-137, 2013.

[20] D. Buoro, P. Pinamonti, and M. Reini, "Optimization of a Distributed Cogeneration System with solar district heating," Applied Energy, vol. 124, pp. 298-308, 2014.

[21] T. Wakui, T. Kinoshita, and R. Yokoyama, "A mixed-integer linear programming approach for cogeneration-based residential energy supply networks with power and heat interchanges," Energy, vol. 68, pp. 29-46, 2014.

[22] E. D. Mehleri, H. Sarimveis, N. C. Markatos, and L. G. Papageorgiou, "A mathematical programming approach for optimal design of distributed energy systems at the neighbourhood level," Energy, vol. 44, pp. 96-104, 2012.

[23] S. Bracco, G. Dentici, and S. Siri, "Economic and environmental optimization model for the design and the operation of a combined heat and power distributed generation system in an urban area," Energy, vol. 55, pp. 1014-1024, 2013.

[24] C. Weber and N. Shah, "Optimisation based design of a district energy system for an eco-town in the United Kingdom," Energy, vol. 36, pp. 1292-1308, 2011.

[25] A. Omu, R. Choudhary, and A. Boies, "Distributed energy resource system optimisation using mixed integer linear programming," Energy Policy, vol. 61, pp. 249-266, 2013. 
[26] J. Keirstead, N. Samsatli, N. Shah, and C. Weber, "The impact of CHP (combined heat and power) planning restrictions on the efficiency of urban energy systems," Energy, vol. 41, pp. 93-103, 2012.

[27] E. D. Mehleri, H. Sarimveis, N. C. Markatos, and L. G. Papageorgiou, "Optimal design and operation of distributed energy systems: Application to Greek residential sector," Renewable Energy, vol. 51, pp. 331-342, 2013.

[28] J. Söderman and F. Pettersson, "Structural and operational optimisation of distributed energy systems," Applied Thermal Engineering, vol. 26, pp. 1400-1408, 2006.

[29] Y. Yang, S. Zhang, and Y. Xiao, "Optimal design of distributed energy resource systems coupled with energy distribution networks," Energy, vol. 85, pp. 433-448, 6/1/ 2015.

[30] B. Morvaj, R. Evins, and J. Carmeliet, "Optimization framework for distributed energy systems with integrated electrical grid constraints," Applied Energy, vol. 171, pp. 296-313, 6/1/ 2016.

[31] A. K. Basu, A. Bhattacharya, S. Chowdhury, and S. P. Chowdhury, "Planned Scheduling for Economic Power Sharing in a CHP-Based Micro-Grid," IEEE Transactions on Power Systems, vol. 27, pp. 30-38, 2012.

[32] G. Cardoso, M. Stadler, M. C. Bozchalui, R. Sharma, C. Marnay, A. Barbosa-Póvoa, and P. Ferrão, "Optimal investment and scheduling of distributed energy resources with uncertainty in electric vehicle driving schedules," Energy, vol. 64, pp. 17-30, 2014.

[33] "Distributed Energy Resources Web Optimization Service (WebOpt)," Grid Integration Group, Lawrence Berkeley National Lab, 2015. [Online]. Available: https://buildingmicrogrid.lbl.gov/projects/distributed-energy-resources-web.

[34] O. Bailey, C. Creighton, R. Firestone, C. Marnay, and M. Stadler, "Distributed energy resources in practice: A case study analysis and validation of LBNL's customer adoption model," Lawrence Berkeley National Laboratory, LBNL-52753, 2003. [Online]. Available: http://eetd.lbl.gov/sites/all/files/publications/report-lbnl-52753.pdf

[35] A. Mammoli, M. Stadler, N. DeForest, H. Barsun, R. Burnett, and C. Marnay, "Software-as-aService Optimised Scheduling of a Solar-Assisted HVAC System with Thermal Storage," in Proc. 2013 International Conference on Microgeneration and Related Technologies, 2013.

[36] C. B. Jones, M. Robinson, H. Barsun, L. Ghanbari, A. Mammoli, S. Mashayekh, W. Feng, and C. Marnay, "Software-as-a-Service Optimal Scheduling of New Mexico Buildings," in Proc. 2015 ECEEE 2015 Summer Study on Energy Efficieny, June, 2015.

[37] S. Bolognani and S. Zampieri, "On the Existence and Linear Approximation of the Power Flow Solution in Power Distribution Networks," IEEE Transactions on Power Systems, vol. PP, pp. 1-10, 2015.

[38] J. F. Franco, M. J. Rider, M. Lavorato, and R. Romero, "A mixed-integer LP model for the reconfiguration of radial electric distribution systems considering distributed generation," Electric Power Systems Research, vol. 97, pp. 51-60, 2013.

[39] "Commercial reference buildings," Department of Energy, [Online]. Available: http://energy.gov/eere/buildings/commercial-reference-buildings. 